\title{
2666. Evaluation and numerical simulation of soil type effects on seismic soil-structure interaction response of RC structures
}

\author{
Elyar Zafarkhah ${ }^{1}$, Morteza Raissi Dehkordi ${ }^{2}$ \\ Iran University of Science and Technology, Tehran, Iran \\ ${ }^{2}$ Corresponding author \\ E-mail: ${ }^{1} E_{-}$zafarkhah@civileng.iust.ac.ir, ${ }^{2}$ mraissi@iust.ac.ir
}

Received 25 February 2017; received in revised form 17 June 2017; accepted 26 June 2017 DOI https://doi.org/10.21595/jve.2017.18286

Abstract. The present study is aimed at determining the effect of variability in soil type and structure height on soil-structure system responses. In order to explore this innovative idea, a wide range of soil types and structure heights are assumed, and the responses are analyzed with respect to changes in soil type and structure height. It is intended to address the three-fold problem of determining under what circumstances soil-structure interaction (SSI) exerts significant effects on the results, on what condition it could be ignored, and whether taking account of SSI leads to conservative results. To verify the numerical models, the results are compared with those derived from the NEHRP method. Five planar concrete frames are examined under the action of thirty earthquake records. Seven types of soil are considered. For modeling the soil-structure system, the direct method is employed. The plastic behavior of the soil is formulated based on the multi-surface (nested surfaces) concept; the yield surfaces of sand are of the Drucker-Prager type, and those of clay are of the Von Mises type. The exact Incremental Dynamic Analysis (IDA) is adopted for analyzing the soil-structure system. The results indicate that, for sandy soils, the SSI impact is greater for looser sub-soils. For clayey soils, the medium clay has the most powerful SSI effect. For low and medium rise buildings, the SSI effect is more profound as the structure becomes taller, but for high rise buildings, the SSI effect wears off with increasing height.

Keywords: soil-structure interaction, IDA method, nonlinear dynamic analysis.

\section{Introduction}

Although seismic waves travel mainly through rock in their course to the ground surface, the last portion of that propagation is often through soil, and the characteristics of the soil can greatly influence the nature of shaking at the ground surface [1]. Based on many previous researches, it is recognized that considering the SSI may significantly affect the response of the structure to the earthquake. The SSI affects different structures differently; it depends on the characteristics of the structure, the soil, and the earthquake record. In some circumstances, the effect could be ignored, but it could prove highly significant in other cases. Since accounting for SSI effects entails following an inherently complicated procedure, SSI effects are ignored in the majority of design codes, presuming that the inattention to soil-structure interaction yields conservative results [2]. The presumption "neglecting the SSI gives conservative results" is not always valid, and the SSI may even considerably increase the responses of structures at times [3]. Accordingly, it seems more appropriate to take the SSI effect into account; one would also benefit from the effect if it introduces a conservative change. In fact, the subsoil provides a flexible base, reduces the stiffness, and increases the deformations and damping [4]. On the other hand, it could affect the frequency content of the incoming seismic motions.

The effect of local soil and geologic conditions on the intensity of ground shaking and earthquake damage has been known for many years. MacMurdo [5] noted that "buildings situated on rock were not by any means affected as much as those whose foundations did not reach the bottom of the soil" in the 1819 earthquake in Cutch, India. Mallet [6], in his report on the 1857 Neapolitan earthquake, reported the effect of local geologic conditions on structural damage. Many researchers have studied the behavior of structures supported on shallow foundations; 
Chopra and Yim [7], modeled the behavior of shallow foundations using Winkler springs. They concluded that taking the SSI effect into account causes a reduction in the moment demand of the structures. ATC 40 [8] believes that stiff and strong foundations do not always surpass flexible and weak foundations; in fact, flexible foundations increase the deformation, leading to a drop in the demands. Spyrakos et al studied the SSI effect on base isolated buildings [9], concluding that the SSI effects for squat structures founded on low-stiffness soil stratum are deeply significant. Zhang and Tang [10] demonstrated that ductility demands may dramatically increase in case of a compliant foundation. The SSI effect on the seismic behavior of multi degree-of-freedom (MDOF) systems was assessed by Dutta et al [11] and Barcena and Esteva [12]. Tang and Zhang performed a comprehensive probabilistic seismic demand analysis of shear walls considering the SSI effect [13]. Many other researches such as Raychowdhury and Prishati [14], Ganjavi and Hao [15, 16] and Abedi-Nik and Khoshnudian [17] have been done on the SSI effect. Afterwards, Ganjavi, Hao and Hajirasouliha [18] underlined the importance of higher modes for soil-structure systems in comparison with fixed based structures. Soil-underground structure static and dynamic interaction was studied by Haiyang [19]. Some researchers tried to compare the experimental observations with the analytical results obtained while taking the SSI into account; examples include [20, 21] and [22]. The role of SSI effect on isolated structures was studied by Tsai and Hsueh [23]. Examining the effects of soil-structure interaction on the deflection modification factor of buildings was another interesting subject that captured the attention of researchers such as Abedi-Nik and Khoshnoudian [24].

As noted above, not all of the findings produced in the previous researches are consonant with each other; some of them are even contradictory. All of them have argued for the strong effect of SSI on the behavior of structures, but arrived at different conclusions about the variations in the structural behavior. Therefore, these investigations fail to provide any conclusive evidence on the way the structural responses are affected by the soil type. This discrepancy in the conclusions is very likely due to the fact that the structures and soil types studied were all different. This is the reason why the present research covers disparate structures and soil types. The results of the present study and those of the previous studies fit together for sandy soils but not for soft clay soils.

\section{Characteristics of concrete frames, soil and earthquake records}

Geometric and material nonlinearity in the superstructure, the foundation and the soil could cause some nonlinearity in soil-structure systems. The nonlinearity may originate from diverse phenomena such as: 1) yielding of seismic-force-resisting elements in the superstructure; 2) yielding of soil, 3) gapping between the foundation and soil, which tends to occur in situations such as base uplift or separation of foundation sidewalls from the surrounding material; and 4) yielding of foundation elements [25]. Most of the researches conducted on nonlinear SSI behavior have assumed either a nonlinear structure with a linear/equivalent-linear soil or a linear structure with a soil capable of yielding.

The literature on the subject shows that material and geometric nonlinearities in the soil may be beneficial to the seismic response of a structure. In order to dissipate the energy and protect the structure, Gajan and Kutter [26] suggested revising the foundation design strategy by allowing for significant yielding within either the foundation or the immediate soil in the vicinity of the foundation.

In the present paper it is intended to consider the likely scenario. For this reason, the soil and the structure are both assumed to be nonlinear. The 2D nonlinear analytical models of soil-structure systems were developed for the nonlinear dynamic analysis with OpenSEES software [27]. 


\subsection{Characteristics of the frames}

In the present study, five planar concrete moment resisting frames are examined. The frames have 3 bays and 3, 6, 9, 12 and 15 stories. The bay length and the story height are 5 and 3 meters respectively. The moment resisting concrete frames have been designed with a peak ground acceleration (PGA) value equal to $0.35 \mathrm{~g}$ and class B soil according to INBR-6 (Iranian National Building Regulations, Section 6). The dead load on the beams is assumed to be $24500 \mathrm{~N} / \mathrm{m}$ plus the self-weight of the beams, and the live loads on the beams are assumed to be $9800 \mathrm{~N} / \mathrm{m}$. The yield stress of the bar material is equal to $4 \times 10^{8} \mathrm{~Pa}$, and the concrete strength is assumed to be $25 \times 10^{6} \mathrm{~Pa}$. The material constitutive models are presented in Fig. 1. The second-order effects are accurately accounted for through the formulation of large displacements. For the confined and unconfined concrete constitutive models, the Kent-Scott-Park model [28] is employed. The constitutive parameters of this model are shown in Fig. 1 and explained below:

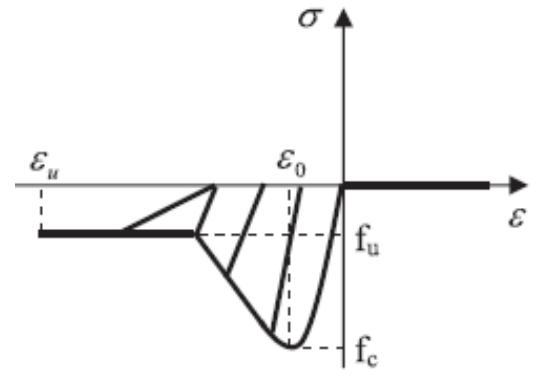

a) Concrete

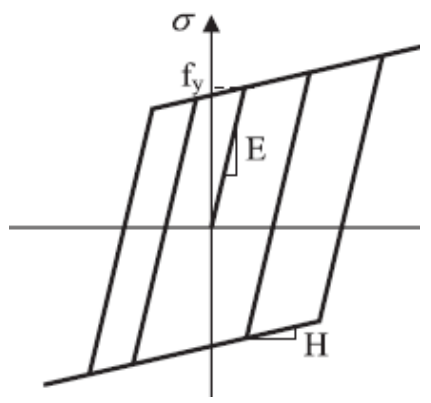

b) Steel

Fig. 1. Material constitutive models: $f_{c}$ - concrete peak strength in compression [Pa], $f_{u}$ - residual strength $[\mathrm{Pa}], \varepsilon_{0}-$ strain at peak strength $[\%], \varepsilon_{u}$ - ultimate compressive strain [\%]

The cover and core concrete in the column cross-sections are considered as unconfined and confined concrete respectively. The confined concrete stress-strain relationships are extracted from Saatcioglu and Razvi [29]. Paulay and Priestley [30] suggested the ultimate compressive strain of confined concrete as:

$\varepsilon_{u c}=\varepsilon_{u o}+1.4 \frac{\rho_{v} f_{y h} \varepsilon_{u s}}{f_{c c}}$

where $\varepsilon_{u c}-$ ultimate compressive strain of confined concrete [\%], $\varepsilon_{u o}-$ ultimate compressive strain of unconfined concrete [\%], $\varepsilon_{u s}-$ ultimate strain of reinforcing steel in tensile [\%], $\rho_{v}$ - volumetric ratio of confining steel [\%], $f_{y h}-$ yield stress of confining steel [Pa], $f_{c c}-$ peak strength of confined concrete in compression $[\mathrm{Pa}]$.

The lumped mass matrix of the frames is built by applying the total of dead loads plus $20 \%$ of live loads. The beams and columns are modeled as fiber sections with concrete and reinforcing steel material layers. The characteristics of the cross-sections for columns and beams are illustrated in Tables 1 and 2.

\subsection{Soil modeling procedure}

In the present paper, the soil layers are modeled using isoperimetric four node quadrilateral finite elements with bilinear displacement interpolation. The finite element mesh size is considered to be $2.0 \mathrm{~m}$ in $x$ and $z$ directions. It is assumed that the soil domain is under plane strain conditions with a constant soil thickness equal to the inter-frame distance. The material of the clay soil is modeled using a modified pressure-independent multi-yield-surface model with an 
associative flow rule, and the yield surfaces are of the Von Mises type. The material of the sandy soil is modeled using a pressure-dependent relation with a non-associative flow rule to reproduce dilatancy effects. The yield surfaces are of the Drucker-Prager type.

Table 1. Column section of frames

\begin{tabular}{|c|c|c|c|c|c|}
\hline \multicolumn{7}{|c|}{ Column sections } \\
\hline & 3 story & 6 story & 9 story & 12 story & 15 story \\
\hline Story 1 & $0.4 \times 0.4[\mathrm{~m}]$ & $0.5 \times 0.5[\mathrm{~m}]$ & $0.5 \times 0.5[\mathrm{~m}]$ & $0.65 \times 0.65[\mathrm{~m}]$ & $0.8 \times 0.8[\mathrm{~m}]$ \\
\hline Story 2 & $0.4 \times 0.4[\mathrm{~m}]$ & $0.5 \times 0.5[\mathrm{~m}]$ & $0.5 \times 0.5[\mathrm{~m}]$ & $0.65 \times 0.65[\mathrm{~m}]$ & $0.8 \times 0.8[\mathrm{~m}]$ \\
\hline Story 3 & $0.4 \times 0.4[\mathrm{~m}]$ & $0.4 \times 0.4[\mathrm{~m}]$ & $0.5 \times 0.5[\mathrm{~m}]$ & $0.65 \times 0.65[\mathrm{~m}]$ & $0.8 \times 0.8[\mathrm{~m}]$ \\
\hline Story 4 & - & $0.4 \times 0.4[\mathrm{~m}]$ & $0.5 \times 0.5[\mathrm{~m}]$ & $0.65 \times 0.65[\mathrm{~m}]$ & $0.8 \times 0.8[\mathrm{~m}]$ \\
\hline Story 5 & - & $0.4 \times 0.4[\mathrm{~m}]$ & $0.5 \times 0.5[\mathrm{~m}]$ & $0.65 \times 0.65[\mathrm{~m}]$ & $0.8 \times 0.8[\mathrm{~m}]$ \\
\hline Story 6 & - & $0.4 \times 0.4[\mathrm{~m}]$ & $0.4 \times 0.4[\mathrm{~m}]$ & $0.5 \times 0.5[\mathrm{~m}]$ & $0.6 \times 0.6[\mathrm{~m}]$ \\
\hline Story 7 & - & $-\times$ & $0.4 \times 0.4[\mathrm{~m}]$ & $0.5 \times 0.5[\mathrm{~m}]$ & $0.6 \times 0.6[\mathrm{~m}]$ \\
\hline Story 8 & - & - & $0.4 \times 0.4[\mathrm{~m}]$ & $0.5 \times 0.5[\mathrm{~m}]$ & $0.6 \times 0.6[\mathrm{~m}]$ \\
\hline Story 9 & - & - & $0.4 \times 0.4[\mathrm{~m}]$ & $0.5 \times 0.5[\mathrm{~m}]$ & $0.6 \times 0.6[\mathrm{~m}]$ \\
\hline Story 10 & - & - & - & $0.4 \times 0.4[\mathrm{~m}]$ & $0.5 \times 0.5[\mathrm{~m}]$ \\
\hline Story 11 & - & - & - & $0.4 \times 0.4[\mathrm{~m}]$ & $0.5 \times 0.5[\mathrm{~m}]$ \\
\hline Story 12 & - & - & - & $0.4 \times 0.4[\mathrm{~m}]$ & $0.5 \times 0.5[\mathrm{~m}]$ \\
\hline Story 13 & - & - & - & - & $0.4 \times 0.4[\mathrm{~m}]$ \\
\hline Story 14 & - & - & - & - & $0.4 \times 0.4[\mathrm{~m}]$ \\
\hline Story 15 & - & - & - & - & $0.4 \times 0.4[\mathrm{~m}]$ \\
\hline
\end{tabular}

Table 2. Beam section of frames

\begin{tabular}{|c|c|c|c|c|c|}
\hline \multicolumn{7}{|c|}{ Beam Sections } \\
\hline Story 1 & 3 story & 6 story & 9 story & 12 story & 15 story \\
\hline Story 2 & $0.3 \times 0.4[\mathrm{~m}]$ & $0.4 \times 0.5[\mathrm{~m}]$ & $0.4 \times 0.5[\mathrm{~m}]$ & $0.45 \times 0.55[\mathrm{~m}]$ & $0.5 \times 0.65[\mathrm{~m}]$ \\
\hline Story 3 & $0.3 \times 0.4[\mathrm{~m}]$ & $0.4 \times 0.5[\mathrm{~m}]$ & $0.4 \times 0.5[\mathrm{~m}]$ & $0.45 \times 0.55[\mathrm{~m}]$ & $0.5 \times 0.65[\mathrm{~m}]$ \\
\hline Story 4 & $0.3 \times 0.4[\mathrm{~m}]$ & $0.3 \times 0.4[\mathrm{~m}]$ & $0.4 \times 0.5[\mathrm{~m}]$ & $0.45 \times 0.55[\mathrm{~m}]$ & $0.5 \times 0.65[\mathrm{~m}]$ \\
\hline Story 5 & - & $0.3 \times 0.4[\mathrm{~m}]$ & $0.4 \times 0.5[\mathrm{~m}]$ & $0.45 \times 0.55[\mathrm{~m}]$ & $0.5 \times 0.65[\mathrm{~m}]$ \\
\hline Story 6 & - & $0.3 \times 0.4[\mathrm{~m}]$ & $0.4 \times 0.5[\mathrm{~m}]$ & $0.45 \times 0.55[\mathrm{~m}]$ & $0.5 \times 0.65[\mathrm{~m}]$ \\
\hline Story 7 & - & $0.3 \times 0.4[\mathrm{~m}]$ & $0.3 \times 0.4[\mathrm{~m}]$ & $0.4 \times 0.5[\mathrm{~m}]$ & $0.4 \times 0.5[\mathrm{~m}]$ \\
\hline Story 8 & - & - & $0.3 \times 0.4[\mathrm{~m}]$ & $0.4 \times 0.5[\mathrm{~m}]$ & $0.4 \times 0.5[\mathrm{~m}]$ \\
\hline Story 9 & - & - & $0.3 \times 0.4[\mathrm{~m}]$ & $0.4 \times 0.5[\mathrm{~m}]$ & $0.4 \times 0.5[\mathrm{~m}]$ \\
\hline Story 10 & - & - & $0.3 \times 0.4[\mathrm{~m}]$ & $0.4 \times 0.5[\mathrm{~m}]$ & $0.4 \times 0.5[\mathrm{~m}]$ \\
\hline Story 11 & - & - & - & $0.3 \times 0.4[\mathrm{~m}]$ & $0.3 \times 0.4[\mathrm{~m}]$ \\
\hline Story 12 & - & - & - & $0.3 \times 0.4[\mathrm{~m}]$ & $0.3 \times 0.4[\mathrm{~m}]$ \\
\hline Story 13 & - & - & - & $0.3 \times 0.4[\mathrm{~m}]$ & $0.3 \times 0.4[\mathrm{~m}]$ \\
\hline Story 14 & - & - & - & - & $0.3 \times 0.4[\mathrm{~m}]$ \\
\hline Story 15 & - & - & - & - & $0.3 \times 0.4[\mathrm{~m}]$ \\
\hline
\end{tabular}

\subsubsection{Modeling soil domain boundary}

The SSI effects are categorized by FEMA P-750 [31] into inertial interaction effects, kinematic interaction effects, and soil-foundation flexibility effects. On the other hand, the methods that can be used to evaluate the mentioned effects fall into the two categories of direct and substructure approaches. In the direct analysis method, the soil and structure are modeled simultaneously and analyzed as an integrated system. The substructure approach involves dividing the SSI problem into distinct parts that are combined to formulate the complete solution. The superposition inherent in the substructure approach requires making the assumption that the soil-structure system behaves linearly, leading to some error in the results. For this reason, the direct method is the one employed in the present study. Modeling the SSI system for an infinite media entails tackling the problem of modeling domain boundaries. Infinite boundaries have to reflect no waves back into the computational domain and absorb all outgoing waves. Lysmer and Kuhlemeyer [32] proposed the 
standard viscous boundary which is defined by using Eqs. (2-3):

$$
\begin{aligned}
& C_{n}=\alpha \rho v_{p}, \quad v_{p}=\sqrt{\frac{2 G(1-v)}{\rho(1-2 v)},} \\
& C_{s}=b \rho v_{s}, \quad v_{s}=\sqrt{\frac{G}{\rho}}
\end{aligned}
$$

where $C_{n}$ - normal damping $[(\mathrm{N} \times \mathrm{S}) / \mathrm{m}], C_{s}-$ shear damping $[(\mathrm{N} \times \mathrm{S}) / \mathrm{m}], \rho-$ mass density of soil $\left[\mathrm{N} / \mathrm{m}^{2}\right], v-$ Poisson ratio of soil $[\%], v_{p}$ - propagation velocity of dilatational waves $[\mathrm{m} / \mathrm{s}], v_{s}-$ propagation velocity of shear waves $[\mathrm{m} / \mathrm{s}]$.

In the present study, a single zero length element is used to define the Lysmer-Kuhlemeyer dashpot; one end of the Lysmer-Kuhlemeyer dashpot element is fixed against all displacements, while the other end is assigned a restraint of the type equalDOF with the soil node. Two series of dashpots are needed to introduce this boundary into the model. As depicted in Fig. 2, dashpots are oriented normally and tangentially to the boundary of the finite element mesh. The soil layer height on the bedrock is assumed to be 30 meters, and the length of the soil domain, boundary to boundary distance, is considered to be 100 meters.

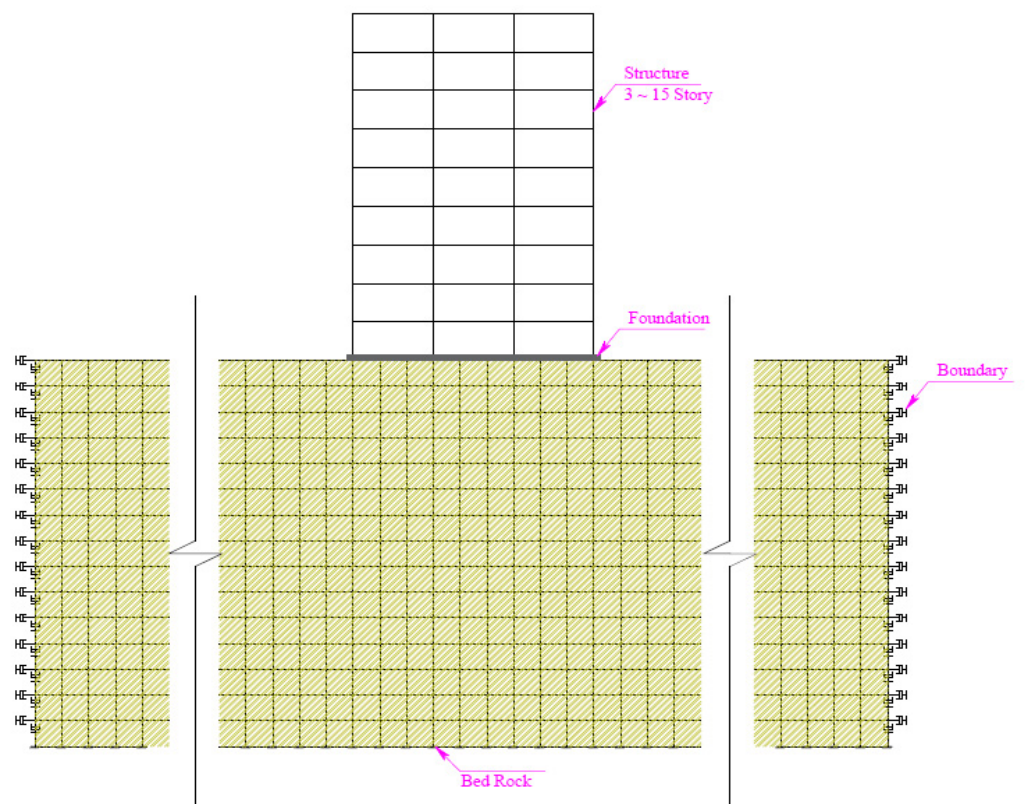

Fig. 2. Soil medium boundary

The soil layer is characterized by the following parameters: $\rho$ - mass density of soil $\left[\mathrm{N} / \mathrm{m}^{3}\right]$, $G_{r}$ - low strain shear modulus [Pa], $B_{r}$ - bulk modulus (At reference mean effective confining pressure) $[\mathrm{Pa}], f-$ friction angle at peak shear strength [Deg], $c$ - apparent cohesion at zero effective confinement (For clay) [Pa], $\gamma_{\max }-$ an octahedral shear strain at which the maximum shear strength is reached [Deg], $P_{r}$ - reference mean effective confining pressure at which $G_{r}, B_{r}$ and $\gamma_{\max }$ are defined $[\mathrm{Pa}]$.

The material damping matrix $C$ of the SSI system is constructed using the Rayleigh method [33], through assembling the corresponding damping matrices of the structure and the soil. The factors of proportionality for damping matrices are calculated for $5 \%$ and $10 \%$ viscous damping for the structure and the soil respectively. The nonlinear equations of structural equilibrium are 
satisfied using the accelerated Newton algorithm based on Krylov subspaces [34]. In the nonlinear time history analysis, the $P-\Delta$ effects are taken into account.

\subsubsection{Soil types}

Soil deposits tend to act as a filter for seismic waves by attenuating the motion at certain frequencies and amplifying it at others. Since soil conditions often vary dramatically over short distances, levels of ground shaking can vary significantly within a small area. One of the most important aspects of geotechnical earthquake engineering practice involves evaluation of the effects of local soil conditions on strong ground motions [1]. Different soil types affect the structure responses differently. In order to address all kinds of soils, seven types of soils, namely loose, medium, medium dense, dense sand, as well as soft, medium, and stiff clay, are considered in the present study. The water table is considered to be below the soil layer. The characteristics of such soil types are presented in Table 3.

Table 3. Characteristics of each soil type

\begin{tabular}{|c|c|c|c|c|c|}
\hline Soil type & $\begin{array}{c}\text { Mass } \\
\text { density }\end{array}$ & $\begin{array}{c}\text { Shear modulus } \\
\text { at low strain }\end{array}$ & $\begin{array}{c}\text { Cohesion at zero } \\
\text { confinement }\end{array}$ & $\begin{array}{c}\text { Peak shear } \\
\text { strain }\end{array}$ & $\begin{array}{c}\text { Friction } \\
\text { angle }\end{array}$ \\
\hline Unit & {$\left[\mathrm{N} / \mathrm{m}^{2}\right]$} & {$\left[\mathrm{N} / \mathrm{m}^{2}\right]$} & {$\left[\mathrm{N} / \mathrm{m}^{2}\right]$} & {$[\mathrm{Deg}]$} & {$[\mathrm{Deg}]$} \\
\hline Loose sand & 17 & 550000 & 0 & 0.1 & 29 \\
\hline Medium sand & 19 & 750000 & 0 & 0.1 & 33 \\
\hline Medium dense sand & 20 & 1000000 & 0 & 0.1 & 37 \\
\hline Dense sand & 21 & 1300000 & 0 & 0.1 & 40 \\
\hline Soft clay & 13 & 130000 & 18 & 0.1 & 0 \\
\hline Medium clay & 15 & 600000 & 37 & 0.1 & 0 \\
\hline Stiff clay & 18 & 1500000 & 75 & 0.1 & 0 \\
\hline
\end{tabular}

Having the characteristics of soil layers in Table 3, one can calculate the shear wave velocity of soil layers using Eq. (4) [1], the values of which are presented in Table 4. Knowing the shear wave velocity, one can calculate the soil layer period based on Eq. (5) [1]. In Table 5, the soil layer period values obtained from Eq. (5) are compared with those obtained from the numerical models:

$v_{s}=\sqrt{\frac{G}{\rho}}$,
$T=\frac{4 H}{V_{s}}$,

where $V_{s}$ - soil shear wave velocity $[\mathrm{m} / \mathrm{s}], G$ - soil shear modulus $[\mathrm{Pa}], \rho$ - soil mass density $\left[\mathrm{N} / \mathrm{m}^{3}\right], H-$ soil layer depth [m], $T$ - soil layer period [s].

Table 4. Shear wave velocity

\begin{tabular}{|c|c|}
\hline Soil shear wave velocity $[\mathrm{m} / \mathrm{s}]$ \\
\hline Soil type & $(G / \rho)^{0.5}$ \\
\hline Loose sand & 179.87 \\
\hline Medium sand & 198.68 \\
\hline Medium dense sand & 223.61 \\
\hline Dense sand & 248.81 \\
\hline Soft clay & 100.00 \\
\hline Medium clay & 200.00 \\
\hline Stiff clay & 288.68 \\
\hline
\end{tabular}


Table 5. Comparing the soil layer period from the experimental equation and Opensees models

\begin{tabular}{|c|c|c|c|}
\hline \multicolumn{3}{|c|}{ Period of soil layer [s] } & \multirow[b]{2}{*}{$\begin{array}{l}\text { (Period based on the model)/ } \\
\text { (Period based on the formula) }\end{array}$} \\
\hline Soil type & $\begin{array}{c}\text { Based on experimental } \\
\text { equation }(4 \mathrm{H} / \mathrm{Vs})\end{array}$ & $\begin{array}{c}\text { Based on } \\
\text { opensees models }\end{array}$ & \\
\hline Loose sand & 0.67 & 0.48816 & 1.37 \\
\hline Medium sand & 0.60 & 0.44238 & 1.37 \\
\hline Medium dense sand & 0.54 & 0.39117 & 1.37 \\
\hline Dense sand & 0.48 & 0.35155 & 1.37 \\
\hline Soft clay & 1.20 & 0.86204 & 1.39 \\
\hline Medium clay & 0.60 & 0.431021 & 1.39 \\
\hline Stiff clay & 0.42 & 0.29862 & 1.39 \\
\hline
\end{tabular}

According to Table 5, the period values calculated in the numerical models are consistent with those calculated with the experimental formula.

\subsection{Characteristics of earthquake records}

One of the most widely used measures of the amplitude of a particular earthquake record is its peak ground acceleration (PGA). Quite often ground motions with high peak accelerations are more destructive than the motions characterized by lower peak accelerations. In some cases, damage may be closely related to the PGA, while in others, it may require several repeated cycles of high amplitude to develop [1]. The concept of an effective acceleration as the acceleration which is most closely related to the structural response and to the damage potential of the earthquake was described by Newmark and Hall [35]. As a result, it can be noted that PGA, frequency content, distance to the fault, and strong motion duration are the most crucial parameters for selecting the records.

In this research, all of the selected records are taken from California State. The criteria for selecting the records are distance to fault, strong motion duration, magnitude of earthquake, and the soil type. The distance to fault values vary from 15 to $36 \mathrm{~km}$. As a result, no near-fault motions with directivity effects are included. The moment magnitude is within the range of 6.0-6.9. The records are listed in Table 6 along with information on the 30 ground motions.

\subsubsection{Intensity measure (IM) scale}

Selecting appropriate parameters for intensity measure (IM) and damage measure (DM) in the IDA analysis is enormously important. Since the IDA analysis is an incremental analysis, these parameters should be scalable to proper seismic intensity values. Moreover, IM and DM are to reflect the dynamic characteristics of the records. Consequently, the structural responses will vary slightly under different earthquake records [36]. In the present study, the peak ground acceleration (PGA) of the records is selected as the seismic intensity measure.

\subsubsection{Damage measure (DM) criterion}

The earthquake-induced damage is represented by DM and derived from the nonlinear dynamic analysis results. Many parameters can be considered as the damage measure criterion, including the maximum inter-story drift, base shear, node rotations, and axial deformation of the elements. Selection of the suitable damage measure criterion depends on its application and the structure characteristics and can vary from structure to structure. In shear buildings, the maximum inter-story drift ratio is correlated with the joint rotations as well as the local and global damages of the structure. Therefore, it can be regarded as the preferred option for DM [36]. In the present study, maximum inter-story drift (the maximum drift of stories) is used as DM to estimate the appropriate structural response against the earthquake records. 
Table 6. Exploited records

\begin{tabular}{|c|c|c|c|c|c|c|}
\hline No & Record & Station & Soil & PGA [g] & Duration [s] & Distance $[\mathrm{km}]$ \\
\hline 1 & Imperial Valley 1979 & Chihuahua & C,D & 0.254 & 40 & 28.7 \\
\hline 2 & Imperial Valley 1979 & Chihuahua & C,D & 0.27 & 40 & 28.7 \\
\hline 3 & Northridge 1994 & Hollywood Storage & C,D & 0.231 & 40 & 25.5 \\
\hline 4 & San Fernando 1971 & Lake Hughes \#1 & ,C & 0.145 & 30 & 25.8 \\
\hline 5 & San Fernando 1971 & Hollywood Stor Lot & $\mathrm{C}, \mathrm{D}$ & 0.21 & 28 & 21.2 \\
\hline 6 & Super Stition Hills 1987 & Wildlife Liquefaction Arrey & $\mathrm{D}$ & 0.134 & 29.805 & 24.7 \\
\hline 7 & Super Stition Hills 1987 & Wildlife Liquefaction Arrey & , D & 0.134 & 29.805 & 24.7 \\
\hline 8 & Super Stition Hills 1987 & Salton Sea Wildlife Refuge & $\bar{D}, \mathrm{D}$ & 0.119 & 21.89 & 21.7 \\
\hline 9 & Super Stition Hills 1987 & Plaster City & C,D & 0.186 & 22.23 & 21 \\
\hline 10 & Super Stition Hills 1987 & Calipatria Fire Station & $\mathrm{C}, \mathrm{D}$ & 0.247 & 22.11 & 28.3 \\
\hline 11 & Landers 1992 & Barstow & $\mathrm{B}, \mathrm{D}$ & 0.135 & 40 & 36.1 \\
\hline 12 & Cape Mendocino 1992 & Rio Dell Overpass & C,B & 0.385 & 36 & 18.5 \\
\hline 13 & Cape Mendocino 1992 & Rio Dell Overpass & C,B & 0.549 & 36 & 18.5 \\
\hline 14 & Coalinga 1983 & Parkfield - Fault Zone 3 & ,D & 0.164 & 40 & 36.4 \\
\hline 15 & Whittier Narrows 1987 & Beverly Hills & $\mathrm{B}, \mathrm{C}$ & 0.126 & 37.4 & 30.3 \\
\hline 16 & Northridge, 1994 & LA, Baldwin Hills & $\mathrm{B}, \mathrm{B}$ & 0.239 & 40 & 31.3 \\
\hline 17 & Imperial Valley, 1979 & El Centro Array \#12 & C,D & 0.143 & 39 & 18.2 \\
\hline 18 & Loma Prieta, 1989 & Anderson Dam Downstream & $\mathrm{B}, \mathrm{D}$ & 0.24 & 39.6 & 21.4 \\
\hline 19 & Loma Prieta, 1989 & Anderson Dam Downstream & $\mathrm{B}, \mathrm{D}$ & 0.244 & 39.6 & 21.4 \\
\hline 20 & Loma Prieta, 1989 & Agnews State Hospital & C,D & 0.159 & 40 & 28.2 \\
\hline 21 & Loma Prieta, 1989 & Anderson Dam Downstream & $\mathrm{B}, \mathrm{D}$ & 0.244 & 39.6 & 21.4 \\
\hline 22 & Loma Prieta, 1989 & Coyote Lake Dam Downstream & $\mathrm{B}, \mathrm{D}$ & 0.179 & 40 & 22.3 \\
\hline 23 & Imperial Valley, 1979 & Cucapah & C,D & 0.309 & 40 & 23.6 \\
\hline 24 & Loma Prieta, 1989 & Sunnyvale Colton Ave & C,D & 0.207 & 39.25 & 28.8 \\
\hline 25 & Imperial Valley, 1979 & El Centro Array \#13 & C,D & 0.117 & 39.5 & 21.9 \\
\hline 26 & Imperial Valley, 1979 & Westmoreland Fire Station & C,D & 0.074 & 40 & 15.1 \\
\hline 27 & Loma Prieta, 1989 & Sunnyvale Colton Ave & C,D & 0.209 & 39.25 & 28.8 \\
\hline 28 & Imperial Valley, 1979 & El Centro Array \#13 & C,D & 0.139 & 39.5 & 21.9 \\
\hline 29 & Imperial Valley, 1979 & Westmoreland Fire Station & C,D & 0.11 & 40 & 15.1 \\
\hline 30 & Loma Prieta, 1989 & Hollister Diff. Array &,$- \mathrm{D}$ & 0.269 & 39.65 & 25.8 \\
\hline
\end{tabular}

\section{Period lengthening due to SSI effect; comparison between numerical model results and those computed based on NEHRP method}

NEHRP Consultant Joint Venture, a joint venture of the Applied Technology Council (ATC) and the Consortium of Universities for Research in Earthquake Engineering (CUREE), published a report in 2012 [25] which attempted to devise a practical method for considering the SSI effect.

According to NEHRP, the SSI effects fall into the three categories of inertial interaction effects, kinematic interaction effects, and soil-foundation flexibility effects. The terms kinematic and inertial interaction were introduced by Kausel [37].

In the present research, the verification and validation of the numerical models are performed with the characteristics presented in NEHRP report.

\subsection{Soil structure system period resulted from numerical models}

The period of the rigid based structures and the soil structure systems obtained from Opensees models are presented in Tables 7 and 8 respectively.

The period lengthening pattern produced by the SSI effect is shown in Table 9. In this table, it can be seen that considering the SSI raises the period value from $1 \%$ to $20 \%$. Nevertheless, the 3 story frame situated on soft clay is an exception as the period lengthening due to considering the soil is about $56 \%$; it could be due to the fact that "the 3 story concrete frame has a very high natural frequency, and the soft clay is characterized by a very low one; therefore, the decline in 
the frequency due to considering a soft clay under the 3 story frame could be substantial".

Table 7. Rigid based structure periods (from Opensees models)

\begin{tabular}{|c|c|c|c|c|c|}
\hline \multicolumn{7}{|c|}{ Rigid based structure period [s] - 1st mode } \\
\hline Structure & 3 Story & 6 Story & 9 Story & 12 Story & 15 Story \\
\hline Rigid based structure & 0.55906 & 0.93873 & 1.23788 & 1.4931 & 1.89771 \\
\hline
\end{tabular}

Table 8. Soil-structure system periods (from Opensees models)

\begin{tabular}{|c|c|c|c|c|c|}
\hline \multicolumn{7}{|c|}{ Soil-structure system period [s] - 1st mode } \\
\hline Soil type & 3 Story & 6 Story & 9 Story & 12 Story & 15 Story \\
\hline Loose sand & 0.57851 & 0.96221 & 1.2808 & 1.56913 & 2.00404 \\
\hline Medium sand & 0.57123 & 0.95583 & 1.2695 & 1.54937 & 1.97654 \\
\hline Medium dense sand & 0.56684 & 0.95094 & 1.26073 & 1.53401 & 1.95521 \\
\hline Dense sand & 0.56466 & 0.94804 & 1.25541 & 1.52459 & 1.94203 \\
\hline Soft clay & 0.875218 & 1.0431 & 1.396666 & 1.76139 & 2.26807 \\
\hline Medium clay & 0.57138 & 0.956671 & 1.271318 & 1.55299 & 1.9821 \\
\hline Stiff clay & 0.563049 & 0.94571 & 1.251175 & 1.51715 & 1.93175 \\
\hline
\end{tabular}

Table 9. Period lengthening caused by SSI (from Opensees models)

\begin{tabular}{|c|c|c|c|c|c|}
\hline \multicolumn{7}{|c|}{$T^{\prime} / T-1$ st mode } \\
\hline Soil type/No. story & 3 Story & 6 Story & 9 Story & 12 Story & 15 Story \\
\hline Loose sand & 1.034791 & 1.0250125 & 1.034672 & 1.05092 & 1.05603 \\
\hline Medium sand & 1.021769 & 1.0182161 & 1.025544 & 1.03769 & 1.04154 \\
\hline Medium dense sand & 1.013916 & 1.0130069 & 1.018459 & 1.0274 & 1.0303 \\
\hline Dense sand & 1.010017 & 1.0099177 & 1.014161 & 1.02109 & 1.02335 \\
\hline Soft clay & 1.565517 & 1.1111821 & 1.128273 & 1.17969 & 1.19516 \\
\hline Medium clay & 1.022037 & 1.019112 & 1.027012 & 1.04011 & 1.04447 \\
\hline Stiff clay & 1.007135 & 1.0074356 & 1.01074 & 1.01611 & 1.01794 \\
\hline
\end{tabular}

Table 9 yields the following two results:

Result 1: The period lengthening grows stronger as the soil type turns more flexible.

Result 2: The longer the structure, the higher the period lengthening.

It should be noted that the SSI effect on period lengthening is not precisely the same as its effect on structural responses such as frame displacement or element stresses.

\subsection{Soil-structure system period obtained from NEHRP}

NEHRP presents a number of period lengthening graphs which indicate the period lengthening caused by SSI. Such graphs are depicted here in Fig. 3. NEHRP presents the graphs for h/B values equal to 1,2 , and 4 and for $h / B$ values equal to $0.5,1.5$, and 2.5 (corresponding to the frames studied herein), which are generated by interpolation.

The expressions $h / V_{s} T^{\prime}$ and $\mathrm{h} / \mathrm{B}$ are shown in Table 10 and 11 respectively for all frames. According to NEHRP, the most important parameter for controlling the significance of SSI effect is the term $h / V_{s} T^{\prime}$ [25], meaning that the higher the value of $h / V_{s} T^{\prime}$, the stronger the effect of SSI. As a matter of fact, the term $h / V_{s} T^{\prime}$ denotes the structure-to-soil stiffness ratio.

According to Table 10, for a certain soil type, the term $h / V_{s} T^{\prime}$ grows with increasing frame height except for the 15 story frame; it is the case for all soil types. This shows that, in the range of low and medium rise buildings, the SSI effects escalate as the structure becomes taller, but for high rise buildings, the SSI effects wear off as the structure becomes taller. NEHRP supports this phenomenon by specifying that "Tall buildings typically have low amounts of $h / V_{s} T^{\prime}$ ratio".

With the help of Fig. 3, Table 10, and Table 11, the period lengthening can be calculated according to the NEHRP method, as presented in Table 12.

By comparing Table 12 with Table 9, it could be inferred that the period lengthening calculated by the numerical models are congruent with those calculated by NEHRP graphs; in this way, the 
models are verified. Accordingly, the NEHRP admits results 1 and 2 mentioned in part 3.1 .

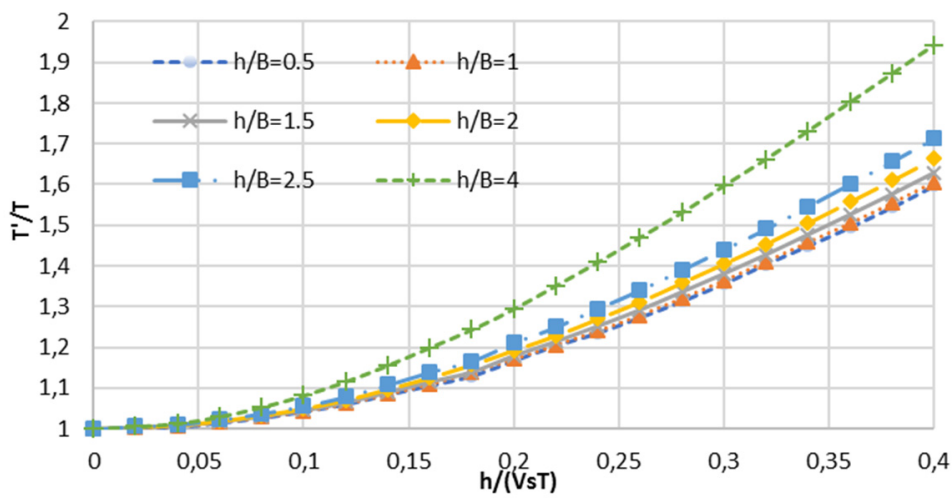

Fig. 3. Period lengthening graph, NEHRP. The parameters are as follows: $h$-structure height $[\mathrm{m}]$, $B$ - foundation width [m], $L$ - foundation length [m], $T^{\prime}-$ structural first mode period [s], $\bar{T}-$ soil-structure system period $[\mathrm{s}], V_{S}-$ soil shear wave velocity $[\mathrm{m} / \mathrm{s}]$

Table 10. $h / V_{s} T^{\prime}$ for studied frames

\begin{tabular}{|c|c|c|c|c|c|}
\hline & \multicolumn{5}{|c|}{$h / V_{s} T^{\prime}$} \\
\cline { 2 - 6 } & $3 \mathrm{St}$ & $6 \mathrm{St}$ & $9 \mathrm{St}$ & $12 \mathrm{St}$ & $15 \mathrm{St}$ \\
\hline Loose sand & 0.08950 & 0.10660 & 0.12126 & 0.13405 & 0.13183 \\
\hline Medium sand & 0.08103 & 0.09651 & 0.10978 & 0.12136 & 0.11935 \\
\hline Medium dense sand & 0.07199 & 0.08575 & 0.09754 & 0.10783 & 0.10605 \\
\hline Dense sand & 0.06470 & 0.07707 & 0.08766 & 0.09691 & 0.09531 \\
\hline Soft clay & 0.16098 & 0.19175 & 0.21811 & 0.24111 & 0.23713 \\
\hline Medium clay & 0.08049 & 0.09587 & 0.10906 & 0.12055 & 0.11856 \\
\hline Stiff clay & 0.05577 & 0.06642 & 0.07556 & 0.08352 & 0.08214 \\
\hline
\end{tabular}

Table 11. $h / B$ for the studied frames

\begin{tabular}{|c|c|}
\hline & $h / B$ \\
\hline $3 \mathrm{St}$ & 0.5 \\
\hline $6 \mathrm{St}$ & 1 \\
\hline $9 \mathrm{St}$ & 1.5 \\
\hline $12 \mathrm{St}$ & 2 \\
\hline $15 \mathrm{St}$ & 2.5 \\
\hline
\end{tabular}

Table 12. The $\bar{T} / T^{\prime}$ ratio - based on NEHRP

\begin{tabular}{|c|c|c|c|c|c|}
\hline & \multicolumn{5}{|c|}{$\bar{T} / T^{\prime}$} \\
\cline { 2 - 6 } & $3 \mathrm{St}$ & $6 \mathrm{St}$ & $9 \mathrm{St}$ & $12 \mathrm{St}$ & $15 \mathrm{St}$ \\
\hline Loose sand & 1.03816 & 1.05489 & 1.07302 & 1.09533 & 1.10219 \\
\hline Medium sand & 1.03160 & 1.04579 & 1.06112 & 1.08007 & 1.08607 \\
\hline Medium dense sand & 1.02512 & 1.03684 & 1.04943 & 1.06506 & 1.07015 \\
\hline Dense sand & 1.02028 & 1.03017 & 1.04074 & 1.05389 & 1.05825 \\
\hline Soft clay & 1.11234 & 1.15853 & 1.20931 & 1.26914 & 1.28412 \\
\hline Medium clay & 1.03120 & 1.04524 & 1.06040 & 1.07915 & 1.08509 \\
\hline Stiff clay & 1.01484 & 1.02268 & 1.03100 & 1.04134 & 1.04484 \\
\hline
\end{tabular}

\section{Effect of local site condition on ground motion}

Local site conditions can profoundly affect all of the important characteristics of earthquake such as amplitude, frequency content, and duration of strong motion. The extent of their influence depends not only on the geometry and properties of the subsurface materials, but also on site topography, and the characteristics of input motion [1]. 
The displacement of soil at the top of the soil layer (ground level) is illustrated in Fig. 4 for various soil types under the action of record number one in Table 6 with PGA $=0.5$. As it is seen, the displacement of the top of the soil layer is completely varied for different soil types. As it was expected, the "Soft Clay" has the lowest natural frequency but the largest amplitude of oscillation. On the contrary, "Dense Sand" has the highest value of frequency but the lowest amplitude of oscillation.

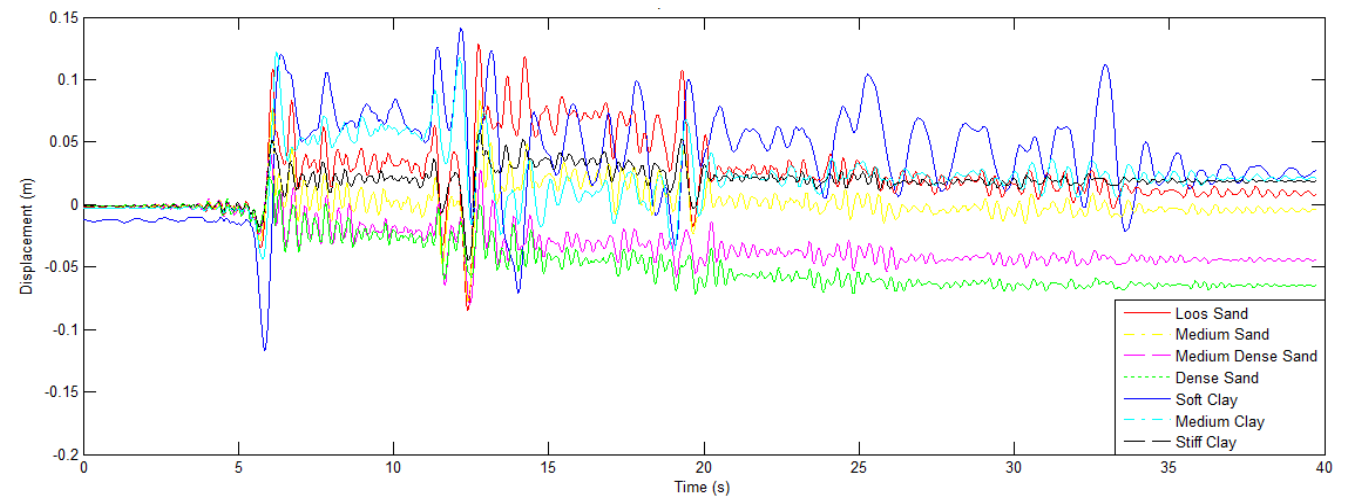

Fig. 4. Displacement of soil at top of the soil layer (ground level) $-\mathrm{PGA}=0.5 \mathrm{~g}$

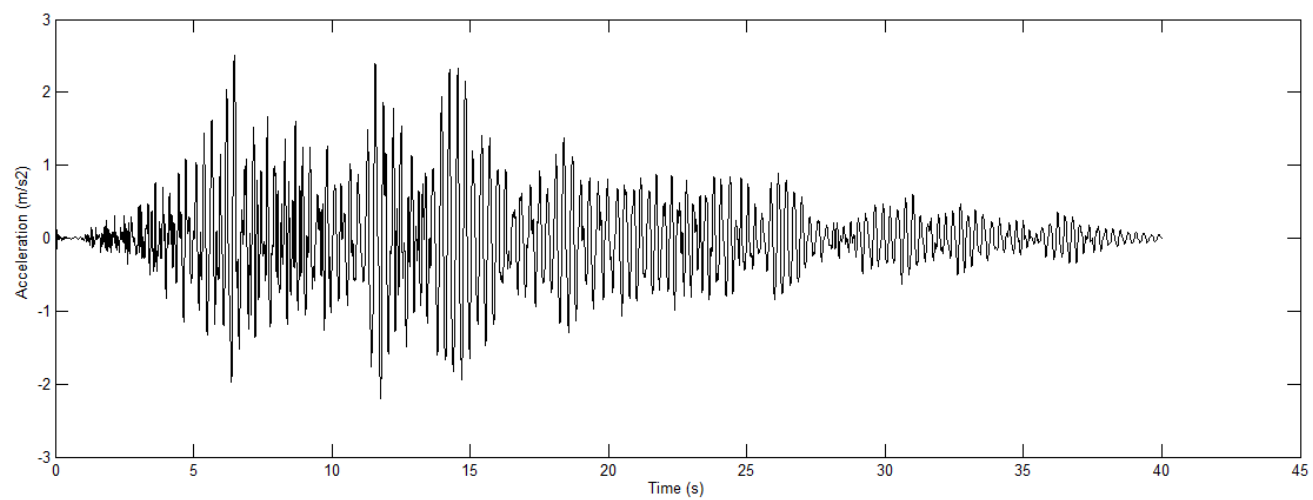

Fig. 5. Acceleration of soil at top of the soil layer (ground level) - dense sand $-\mathrm{Sc}=0.1 \mathrm{~g}$

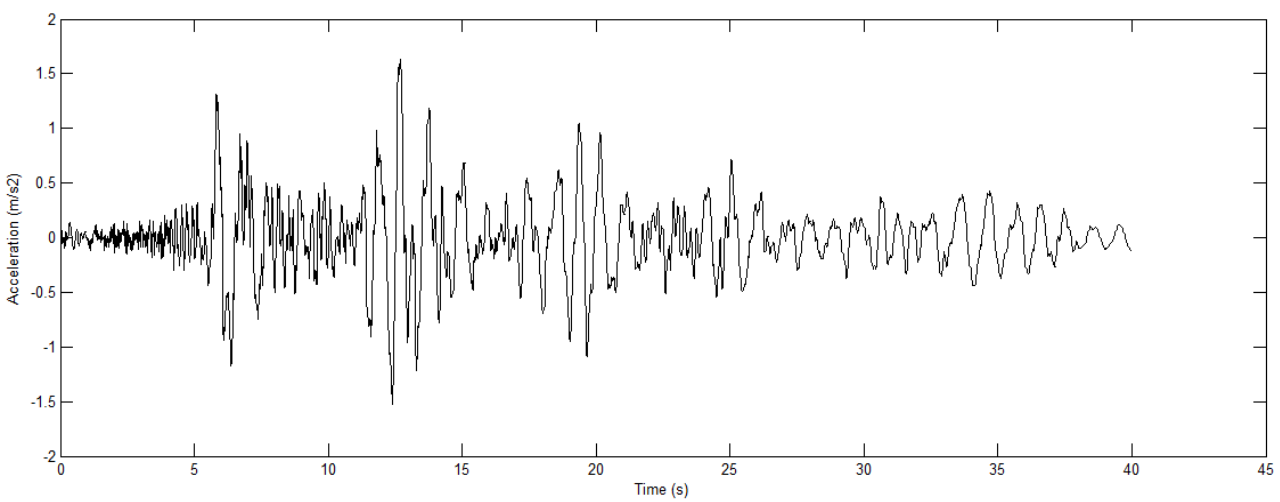

Fig. 6. Acceleration of soil at top of the soil layer (ground level) - soft clay $-\mathrm{Sc}=0.1 \mathrm{~g}$

Results show that every record changes dramatically in frequency content, PGA, Strong motion duration and other properties after passing through the soil layers; the changes are different 
for different soil types. According to Fig. 4, the largest value for the displacement of the top of soil layer belongs to soft clay and loose sand.

Fig. 5 and Fig. 6 illustrate the acceleration at the top of the soil layer for "Dense Sand" and "Soft Clay", representative of the densest and the loosest soil types.

The characteristics of local soil deposits can also affect the extent to which ground motion amplification will occur. This phenomenon can be tracked in Figs. 7 and 8; these figures show the acceleration of the soil top in the frequency domain for dense sand and soft clay respectively. As illustrated in Figs. 7 and 8, softer soils (Soft Clay) amplify low-frequency (long-period) bedrock motion to a greater extent than stiffer soils do. On the contrary, stiffer soils (Dense Sand) amplify high-frequency (low-period) bedrock motion more profoundly than softer soils do.

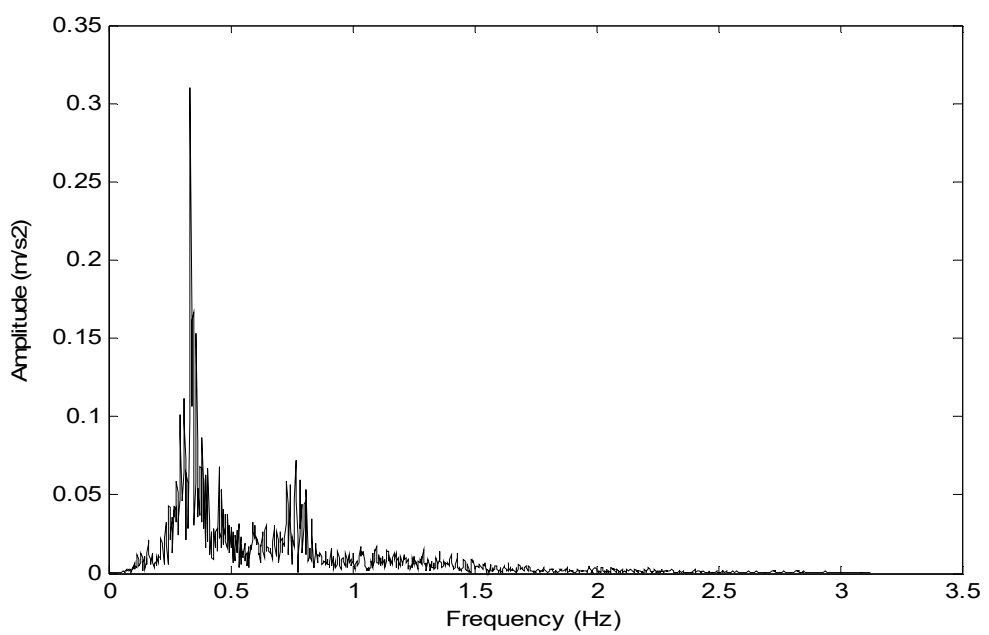

Fig. 7. Acceleration of soil at top of the soil layer (ground level) - dense sand $-\mathrm{Sc}=0.1 \mathrm{~g}$

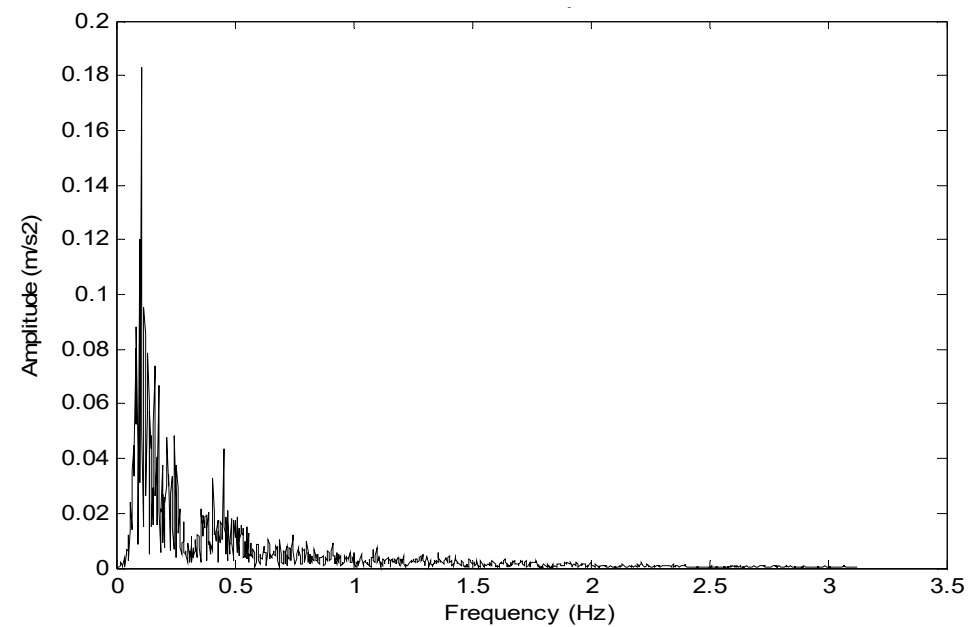

Fig. 8. Acceleration of soil at top of the soil layer (ground level) - soft clay $-\mathrm{Sc}=0.1 \mathrm{~g}$

Therefore, it is expected that low rise structure responses would be amplified on dense soils, and high rise structure responses would be amplified on soft soils. The acceleration of top of the soil layer for different soil types is illustrated in Fig. 9.

As shown in Fig. Fig. 9, sandy soils develop larger amplitudes of acceleration in the frequency domain. The predominant frequency of soft clay and dense sand is the smallest and the largest respectively. 


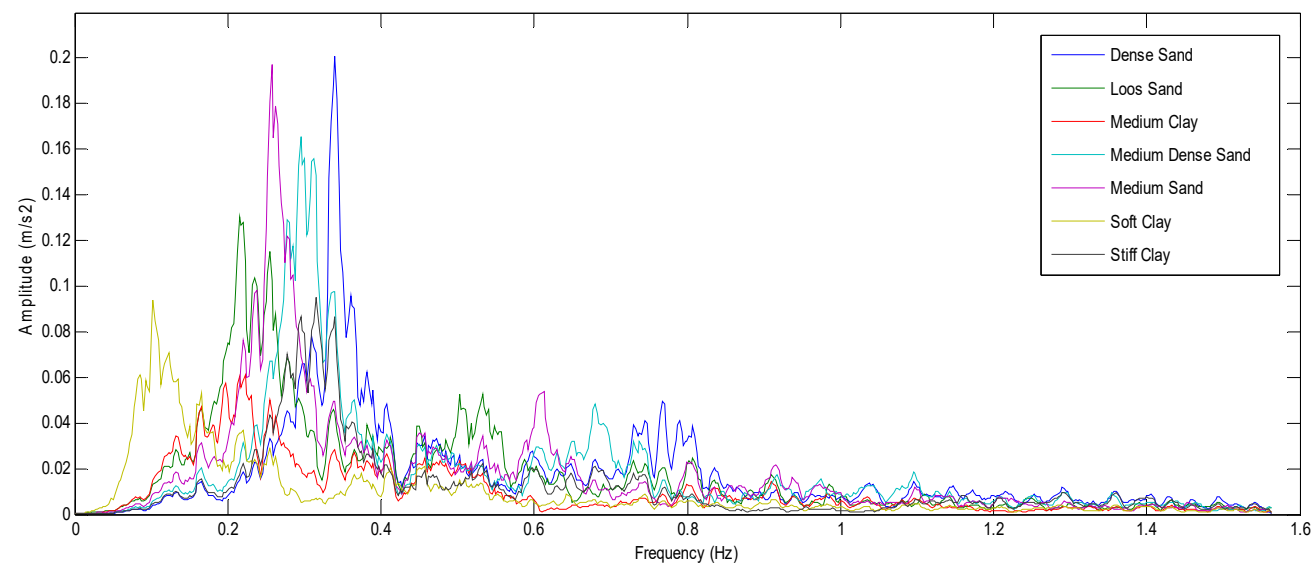

Fig. 9. Comparison of acceleration on top of soil layer for different soil types under the action of $\mathrm{Rec} 01-\mathrm{Sc}=0.1 \mathrm{~g}$ (frequency domain)

\section{SSI effect on the Pushover curve}

The Pushover (PO) curves of the rigid based frames are shown in Fig. 10. Since PO curves express the static behavior of structures, it is expected that considering the SSI effect doesn't greatly affect this curve. The PO curves of the 3 and 15 story frames are illustrated in Fig. 11 and Fig. 12 respectively; these figures prove that the effect of SSI on the PO curves is negligible. Similar results were confirmed by other researchers [38]. In these figures, it is clearly evident that the SSI effect is more marked on high rise buildings than low rise ones.

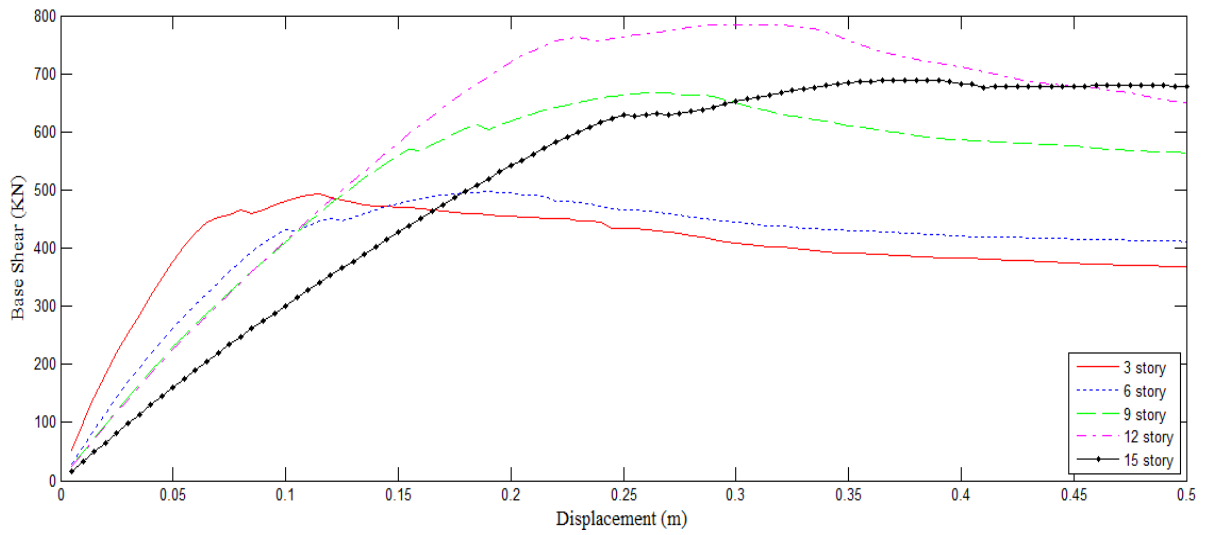

Fig. 10. Pushover curve for all structures - rigid based

\section{Effect of SSI on IDA curve}

Subsoil characteristics affect the IDA curve dramatically. As it was discussed earlier, the subsoil attenuates motion at certain frequencies and amplifies it at others; it also makes the base of the structure non-fixed, i.e. one that tends to rotate about foundation toe. Another important effect of taking the subsoil into account is the alteration of the period and damping. The IDA curves of each frame on different soil types are presented in Figs. 13-17.

According to Figs. 13-17, soil-structure system responses highly depend on the subsoil type. The figures show that, in the case of sandy soils, the drift builds up more considerably as the soil becomes looser. On the other hand, in the case of clayey subsoils, for the 3 to 12 story frames, the stiff clay causes the greatest drift lengthening, and the soft clay leads to the smallest drift 
lengthening. For such frames, the soft clay is the only soil which not only produces no increment but even sometimes some decline in the drift in comparison with the rigid based frame. On the other hand, for the 15 story frame, the soft clay causes the greatest drift lengthening, and the stiff clay produces the lowest drift lengthening values.

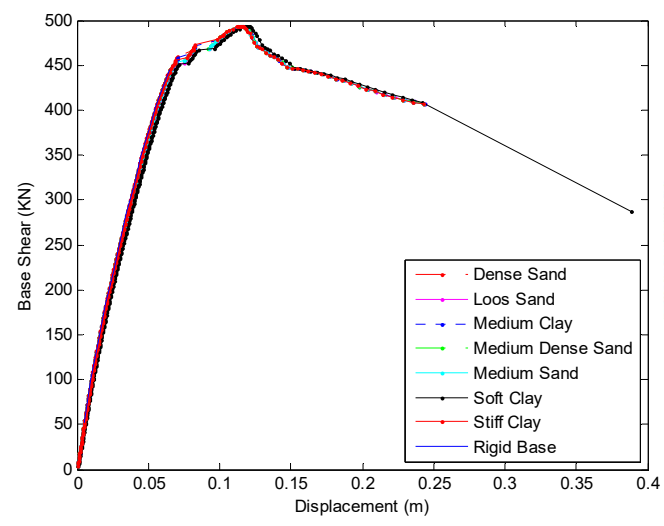

Fig. 11. Pushover curve for 3 story frame - all soil types

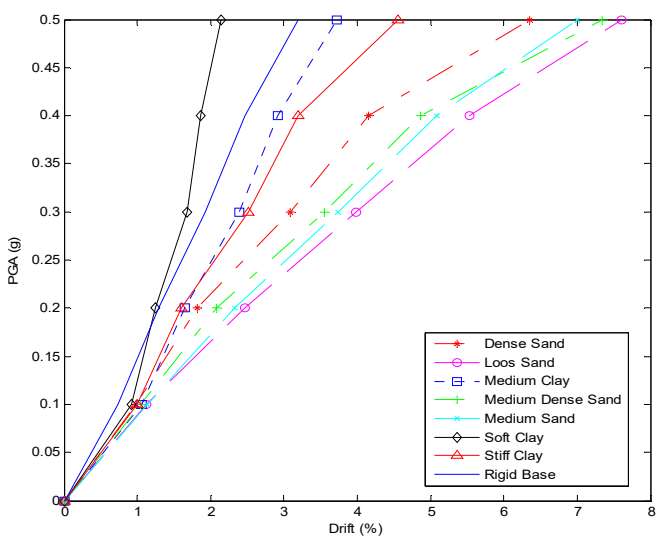

Fig. 13. IDA curve for 3 story frame - all soil types

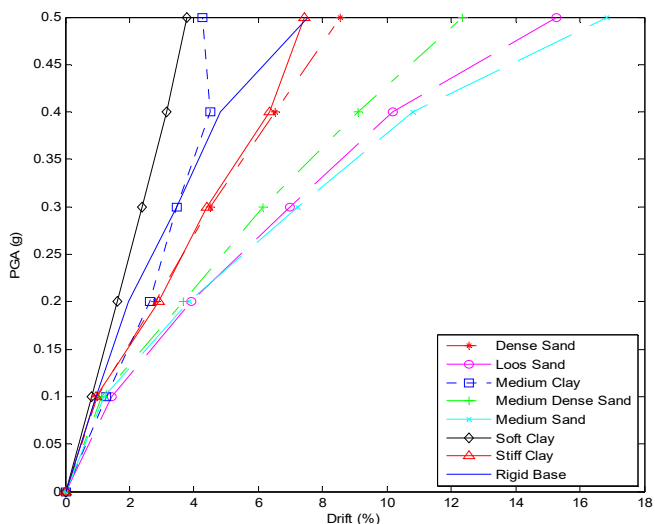

Fig. 15. IDA curve for 9 story frame - all soil types

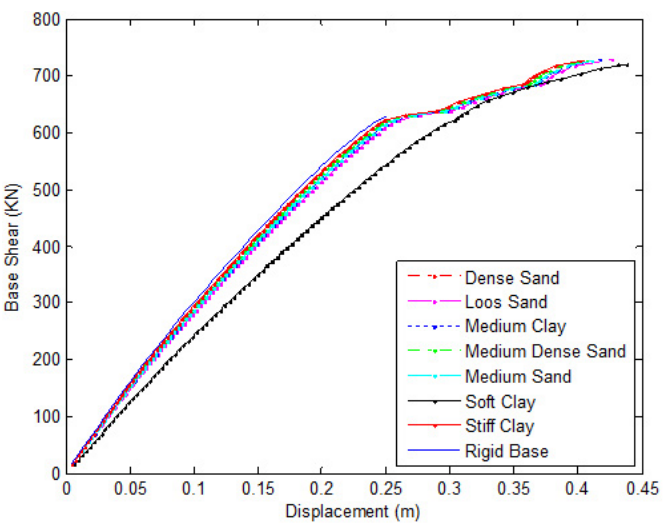

Fig. 12. Pushover curve for 15 story frame - all soil types

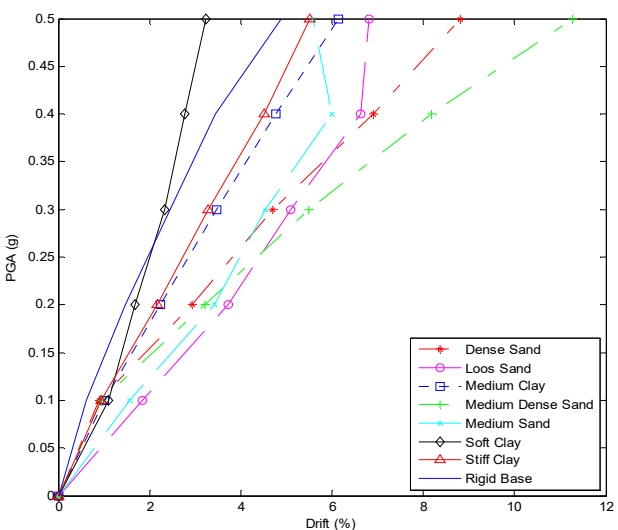

Fig. 14. IDA curve for 6 story frame - all soil types

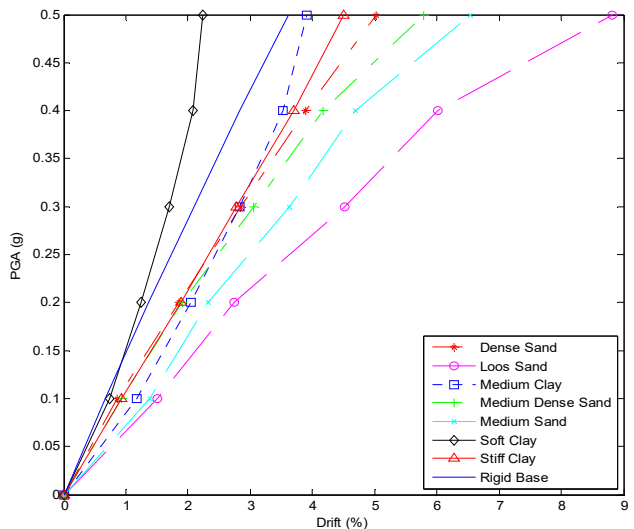

Fig. 16. IDA curve for 12 story frame - all soil types 


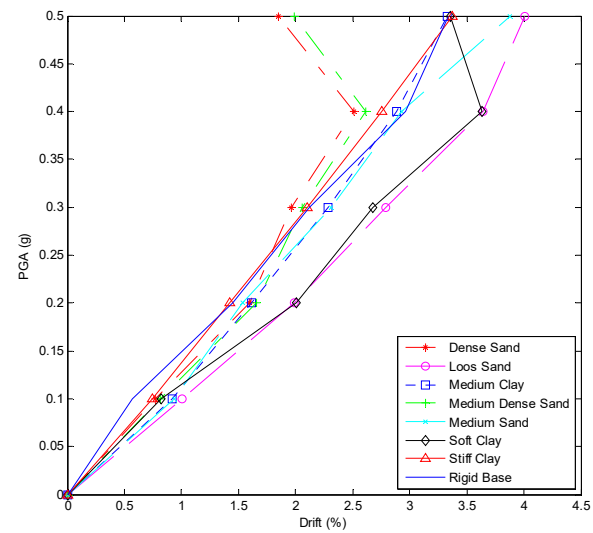

Fig. 17. IDA curve for 15 story frame - all soil types

\section{Evaluating average drift increase caused by SSI}

\subsection{Average drift increase for each frame on different soil types}

It is intended here to figure out the dependence of response augmentation, due to considering SSI, to the frame height and to find the response intensification trend in terms of the number of stories.

According to Table 13, the SSI effect on the average drift value is the most profound for the 6 story frame and the least powerful for the 15 story frame. Based on the resultant average values, it could be said that for low rise structures, as the structure becomes taller, the drift lengthening, as a result of considering SSI, swells. in addition, for medium rise structures, the frame height is not a governing parameter capable of either softening or magnifying the effect of SSI. for high rise structures, the effect of SSI on the drift wears off with increasing structural height. It should be noted that this fact was argued in a different manner in part 3.1.

The most decisive effect of SSI on the drift belongs to the low and medium rise structures. a schematic graph representing the relation between "height of structures" and "drift lengthening caused by SSI" is demonstrated in Fig. 19.

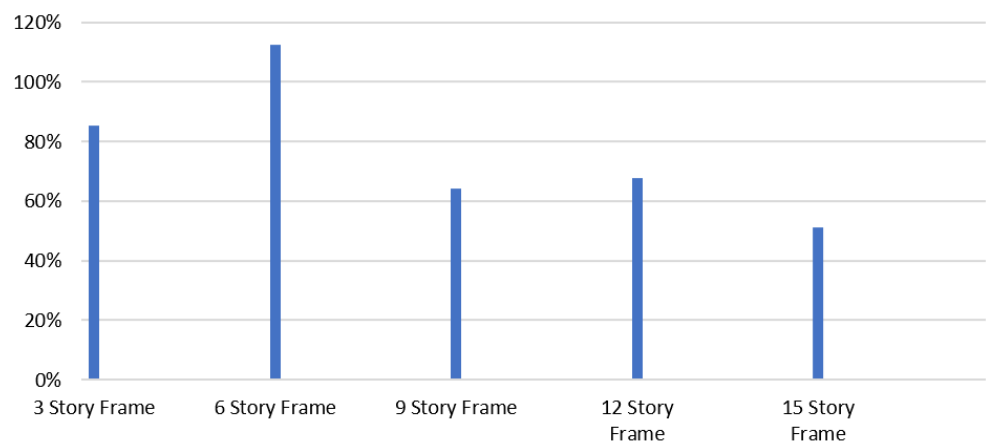

Fig. 18. Average of drift lengthening caused by considering SSI

Based on Fig. 19, it can be stated that, in the case of low rise structures, drift lengthening grows with increasing height of the structure, and for medium rise structures, the frame height doesn't affect the drift lengthening; finally, for tall buildings, considering the SSI leads to a decline in drift lengthening. It is obvious that the most dramatic effect of SSI is produced for medium rise structures. in the case of very tall buildings, drift lengthening caused by SSI approaches zero, meaning that, for such buildings, considering SSI doesn't affect the drift of the structure. 
Table 13. Drift increment due to considering SSI - classified based on story number

\begin{tabular}{|c|c|c|c|c|c|c|c|c|c|c|}
\hline & \multicolumn{5}{|c|}{ Drift Increment (\%) } & \multirow{3}{*}{$\begin{array}{c}\text { Average drift } \\
\text { increment } \\
\text { due to SSI }\end{array}$} & \multirow{3}{*}{$\begin{array}{l}\text { Maximum drift } \\
\text { increment } \\
\text { due to SSI }\end{array}$} & \multirow{3}{*}{$\begin{array}{l}\text { Average } \\
\text { for } \\
\text { each frame }\end{array}$} \\
\hline & & & \multicolumn{5}{|c|}{ PGA $(g)$} & & & \\
\hline & & & \begin{tabular}{|l|l|}
0 & 0.1 \\
\end{tabular} & 0.2 & 0.3 & 0.4 & 0.5 & & & \\
\hline \multirow{7}{*}{$\begin{array}{l}\frac{5}{n} \\
m\end{array}$} & \multirow{7}{*}{ 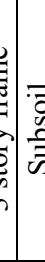 } & Loose sand & $050 \%$ & $91 \%$ & $107 \%$ & $124 \%$ & $139 \%$ & $85 \%$ & $139 \%$ & \multirow{7}{*}{$85 \%$} \\
\hline & & Medium sand & \begin{tabular}{|l|l|}
0 & $54 \%$ \\
\end{tabular} & $81 \%$ & $94 \%$ & $106 \%$ & $120 \%$ & $76 \%$ & $120 \%$ & \\
\hline & & Medium dense sand & $041 \%$ & $61 \%$ & $84 \%$ & $97 \%$ & $130 \%$ & $69 \%$ & $130 \%$ & \\
\hline & & Dense sand & \begin{tabular}{l|l|}
0 & $32 \%$ \\
\end{tabular} & $41 \%$ & $60 \%$ & $68 \%$ & $99 \%$ & $50 \%$ & $99 \%$ & \\
\hline & & Soft clay & $023 \%$ & $-3 \%$ & $-13 \%$ & $-24 \%$ & $-33 \%$ & $-8 \%$ & $23 \%$ & \\
\hline & & Medium clay & $043 \%$ & $28 \%$ & $24 \%$ & $18 \%$ & $17 \%$ & $22 \%$ & $43 \%$ & \\
\hline & & Stiff clay & \begin{tabular}{|l|l|}
0 & $35 \%$ \\
\end{tabular} & $24 \%$ & $31 \%$ & $29 \%$ & $43 \%$ & $27 \%$ & $43 \%$ & \\
\hline \multirow{7}{*}{ 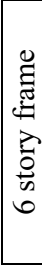 } & \multirow{7}{*}{$\begin{array}{l}= \\
0 \\
0 \\
0 \\
\vdots \\
\text { की }\end{array}$} & Loose sand & $0200 \%$ & $154 \%$ & $108 \%$ & $92 \%$ & $39 \%$ & $99 \%$ & $200 \%$ & \multirow{7}{*}{$112 \%$} \\
\hline & & Medium sand & $0153 \%$ & $133 \%$ & $86 \%$ & $74 \%$ & $14 \%$ & $77 \%$ & $153 \%$ & \\
\hline & & Medium dense sand & \begin{tabular}{|l|l|}
0 & $54 \%$ \\
\end{tabular} & $120 \%$ & $124 \%$ & $137 \%$ & $131 \%$ & $94 \%$ & $137 \%$ & \\
\hline & & Dense sand & $046 \%$ & $100 \%$ & $92 \%$ & $100 \%$ & $80 \%$ & $70 \%$ & $100 \%$ & \\
\hline & & Soft clay & $080 \%$ & $15 \%$ & $-5 \%$ & $-20 \%$ & $-34 \%$ & $6 \%$ & $80 \%$ & \\
\hline & & Medium clay & $064 \%$ & $53 \%$ & $42 \%$ & $38 \%$ & $26 \%$ & $37 \%$ & $64 \%$ & \\
\hline & & Stiff clay & \begin{tabular}{l|l|}
0 & $53 \%$ \\
\end{tabular} & $48 \%$ & $34 \%$ & $31 \%$ & $13 \%$ & $30 \%$ & $53 \%$ & \\
\hline \multirow{7}{*}{ 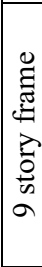 } & \multirow{7}{*}{ 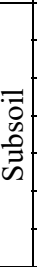 } & Loose sand & \begin{tabular}{|l|l|}
0 & $49 \%$ \\
\end{tabular} & $100 \%$ & $101 \%$ & $111 \%$ & $102 \%$ & $77 \%$ & $111 \%$ & \multirow{7}{*}{$64 \%$} \\
\hline & & Medium sand & \begin{tabular}{l|l|}
$026 \%$ \\
\end{tabular} & $96 \%$ & $108 \%$ & $124 \%$ & $123 \%$ & $79 \%$ & $124 \%$ & \\
\hline & & Medium dense sand & \begin{tabular}{|l|l|}
0 & $18 \%$ \\
\end{tabular} & $87 \%$ & $77 \%$ & $89 \%$ & $64 \%$ & $56 \%$ & $89 \%$ & \\
\hline & & Dense sand & $0.2 \%$ & $42 \%$ & $30 \%$ & $35 \%$ & $13 \%$ & $20 \%$ & $42 \%$ & \\
\hline & & Soft clay & $0-16 \%$ & $-17 \%$ & $-31 \%$ & $-34 \%$ & $-50 \%$ & $-25 \%$ & $0 \%$ & \\
\hline & & Medium clay & \begin{tabular}{|l|l|}
0 & $31 \%$ \\
\end{tabular} & $33 \%$ & $0 \%$ & $-6 \%$ & $-43 \%$ & $3 \%$ & $33 \%$ & \\
\hline & & Stiff clay & $0.0 \%$ & $48 \%$ & $27 \%$ & $32 \%$ & $-2 \%$ & $18 \%$ & $48 \%$ & \\
\hline \multirow{7}{*}{ 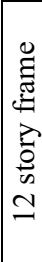 } & \multirow{7}{*}{ 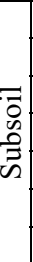 } & Loose sand & $0125 \%$ & $101 \%$ & $116 \%$ & $113 \%$ & $143 \%$ & $100 \%$ & $143 \%$ & \multirow{7}{*}{$68 \%$} \\
\hline & & Medium sand & $0106 \%$ & $70 \%$ & $74 \%$ & $66 \%$ & $81 \%$ & $66 \%$ & $106 \%$ & \\
\hline & & Medium dense sand & 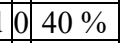 & $39 \%$ & $46 \%$ & $48 \%$ & $60 \%$ & $39 \%$ & $60 \%$ & \\
\hline & & Dense sand & \begin{tabular}{l|l|}
$029 \%$ \\
\end{tabular} & $35 \%$ & $36 \%$ & $38 \%$ & $39 \%$ & $30 \%$ & $39 \%$ & \\
\hline & & Soft clay & \begin{tabular}{|l|l|}
0 & $10 \%$ \\
\end{tabular} & $-9 \%$ & $-19 \%$ & $-26 \%$ & $-38 \%$ & $-14 \%$ & $10 \%$ & \\
\hline & & Medium clay & $076 \%$ & $49 \%$ & $35 \%$ & $25 \%$ & $8 \%$ & $32 \%$ & $76 \%$ & \\
\hline & & Stiff clay & \begin{tabular}{|l|l|}
0 & $40 \%$ \\
\end{tabular} & $38 \%$ & $33 \%$ & $31 \%$ & $24 \%$ & $28 \%$ & $40 \%$ & \\
\hline \multirow{7}{*}{ 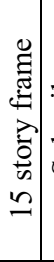 } & \multirow{7}{*}{$\overrightarrow{\bar{n}}$} & Loose sand & \begin{tabular}{|l|l|}
$077 \%$ \\
\end{tabular} & $37 \%$ & $32 \%$ & $23 \%$ & $20 \%$ & $31 \%$ & $77 \%$ & \multirow{7}{*}{$51 \%$} \\
\hline & & Medium sand & \begin{tabular}{l|l|}
0 & $64 \%$ \\
\end{tabular} & $6 \%$ & $9 \%$ & $-1 \%$ & $16 \%$ & $16 \%$ & $64 \%$ & \\
\hline & & Medium dense sand & $044 \%$ & $14 \%$ & $-3 \%$ & $-12 \%$ & $-41 \%$ & $0 \%$ & $44 \%$ & \\
\hline & & Dense sand & \begin{tabular}{|l|l|}
0 & $35 \%$ \\
\end{tabular} & $10 \%$ & $-7 \%$ & $-15 \%$ & $-45 \%$ & $-4 \%$ & $35 \%$ & \\
\hline & & Soft clay & $045 \%$ & $38 \%$ & $26 \%$ & $23 \%$ & $0 \%$ & $22 \%$ & $45 \%$ & \\
\hline & & Medium clay & \begin{tabular}{|l|l|}
0 & $62 \%$ \\
\end{tabular} & $12 \%$ & $8 \%$ & $-3 \%$ & $0 \%$ & $13 \%$ & $62 \%$ & \\
\hline & & Stiff clay & \begin{tabular}{|l|l|}
0 & $31 \%$ \\
\end{tabular} & $-2 \%$ & $-1 \%$ & $-7 \%$ & $1 \%$ & $4 \%$ & $31 \%$ & \\
\hline
\end{tabular}

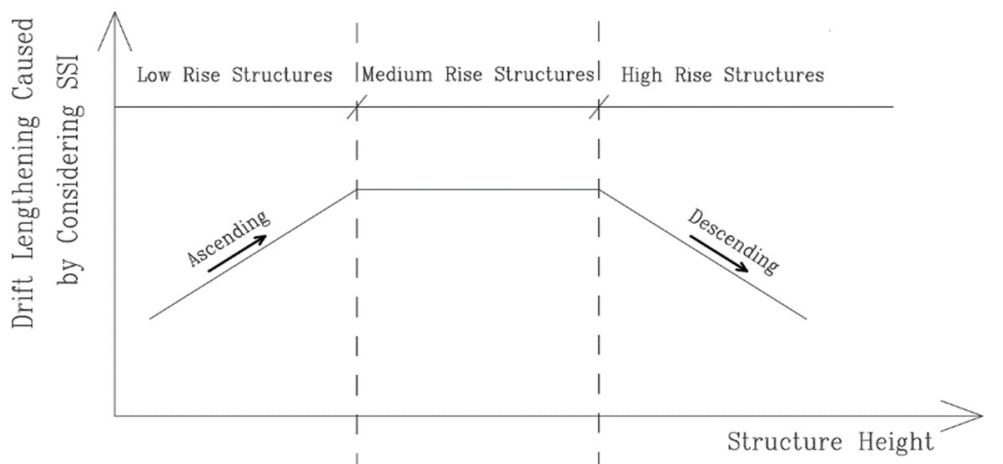

Fig. 19. Schematic graph for relation between "height of structure" and "drift lengthening caused by SSI" 


\subsection{Average drift growth for different frames on the same soil type}

In this part, the dependence of the average of response growth, due to considering SSI, on soil type is examined.

Table 14. Drift increment due to considering SSI - classified based on soil type

\begin{tabular}{|c|c|c|c|c|c|c|c|c|c|c|}
\hline & \multicolumn{6}{|c|}{ Drift increment (\%) } & \multirow{3}{*}{$\begin{array}{l}\text { Average drift } \\
\text { increment } \\
\text { due to SSI }\end{array}$} & \multirow{3}{*}{$\begin{array}{c}\text { Maximum drift } \\
\text { increment } \\
\text { due to SSI }\end{array}$} & \multirow{3}{*}{$\begin{array}{c}\text { Average } \\
\text { for each frame }\end{array}$} \\
\hline & & \multicolumn{6}{|c|}{ PGA $(\mathrm{g})$} & & & \\
\hline Subsoil & $\begin{array}{l}\text { Story } \\
\backslash \text { PGA }\end{array}$ & 0 & 0.1 & 0.2 & 0.3 & 0.4 & 0.5 & & & \\
\hline \multirow{5}{*}{ 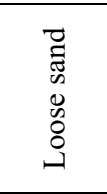 } & 3 Story & 0 & $50 \%$ & $91 \%$ & $107 \%$ & $124 \%$ & $139 \%$ & $85 \%$ & $139 \%$ & \multirow{5}{*}{$134 \%$} \\
\hline & 6 Story & $0 \%$ & $200 \%$ & $154 \%$ & $108 \%$ & $92 \%$ & $39 \%$ & $99 \%$ & $200 \%$ & \\
\hline & 9 Story & $0 \%$ & $49 \%$ & $100 \%$ & $101 \%$ & $111 \%$ & $102 \%$ & $77 \%$ & $111 \%$ & \\
\hline & 12 Story & $0 \%$ & $125 \%$ & $101 \%$ & $116 \%$ & $113 \%$ & $143 \%$ & $100 \%$ & $143 \%$ & \\
\hline & 15 Story & $0 \%$ & $77 \%$ & $37 \%$ & $32 \%$ & $23 \%$ & $20 \%$ & $31 \%$ & $77 \%$ & \\
\hline \multirow{5}{*}{ 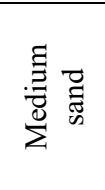 } & 3 Story & $0 \%$ & $54 \%$ & $81 \%$ & $94 \%$ & $106 \%$ & $120 \%$ & $76 \%$ & $120 \%$ & \multirow{5}{*}{$113 \%$} \\
\hline & 6 Story & $0 \%$ & $153 \%$ & $133 \%$ & $86 \%$ & $74 \%$ & $14 \%$ & $77 \%$ & $153 \%$ & \\
\hline & 9 Story & $0 \%$ & $26 \%$ & $96 \%$ & $108 \%$ & $124 \%$ & $123 \%$ & $79 \%$ & $124 \%$ & \\
\hline & 12 Story & $0 \%$ & $106 \%$ & $70 \%$ & $74 \%$ & $66 \%$ & $81 \%$ & $66 \%$ & $106 \%$ & \\
\hline & 15 Story & $0 \%$ & $64 \%$ & $6 \%$ & $9 \%$ & $-1 \%$ & $16 \%$ & $16 \%$ & $64 \%$ & \\
\hline \multirow{5}{*}{ 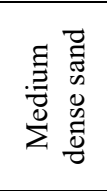 } & 3 Story & $0 \%$ & $41 \%$ & $61 \%$ & $84 \%$ & $97 \%$ & $130 \%$ & $69 \%$ & $130 \%$ & \multirow{5}{*}{$92 \%$} \\
\hline & 6 Story & $0 \%$ & $54 \%$ & $120 \%$ & $124 \%$ & $137 \%$ & $131 \%$ & $94 \%$ & $137 \%$ & \\
\hline & 9 Story & $0 \%$ & $18 \%$ & $87 \%$ & $77 \%$ & $89 \%$ & $64 \%$ & $56 \%$ & $89 \%$ & \\
\hline & 12 Story & $0 \%$ & $40 \%$ & $39 \%$ & $46 \%$ & $48 \%$ & $60 \%$ & $39 \%$ & $60 \%$ & \\
\hline & 15 Story & $0 \%$ & $44 \%$ & $14 \%$ & $-3 \%$ & $-12 \%$ & $-41 \%$ & $0 \%$ & $44 \%$ & \\
\hline \multirow{5}{*}{$\begin{array}{l}\vec{Z} \\
\bar{E} \\
0 \\
0 \\
0 \\
\bar{D} \\
0\end{array}$} & 3 Story & $0 \%$ & $32 \%$ & $41 \%$ & $60 \%$ & $68 \%$ & $99 \%$ & $50 \%$ & $99 \%$ & \multirow{5}{*}{$63 \%$} \\
\hline & 6 Story & $0 \%$ & $46 \%$ & $100 \%$ & $92 \%$ & $100 \%$ & $80 \%$ & $70 \%$ & $100 \%$ & \\
\hline & 9 Story & $0 \%$ & $2 \%$ & $42 \%$ & $30 \%$ & $35 \%$ & $13 \%$ & $20 \%$ & $42 \%$ & \\
\hline & 12 Story & $0 \%$ & $29 \%$ & $35 \%$ & $36 \%$ & $38 \%$ & $39 \%$ & $30 \%$ & $39 \%$ & \\
\hline & 15 Story & $0 \%$ & $35 \%$ & $10 \%$ & $-7 \%$ & $-15 \%$ & $-45 \%$ & $-4 \%$ & $35 \%$ & \\
\hline \multirow{5}{*}{$\begin{array}{l}\frac{\vec{\sigma}}{0} \\
\stackrel{0}{0} \\
0\end{array}$} & 3 Story & $0 \%$ & $23 \%$ & $-3 \%$ & $-13 \%$ & $-24 \%$ & $-33 \%$ & $-8 \%$ & $23 \%$ & \multirow{5}{*}{$32 \%$} \\
\hline & 6 Story & $0 \%$ & $80 \%$ & $15 \%$ & $-5 \%$ & $-20 \%$ & $-34 \%$ & $6 \%$ & $80 \%$ & \\
\hline & 9 Story & $0 \%$ & $-16 \%$ & $-17 \%$ & $-31 \%$ & $-34 \%$ & $-50 \%$ & $-25 \%$ & $0 \%$ & \\
\hline & 12 Story & $0 \%$ & $10 \%$ & $-9 \%$ & $-19 \%$ & $-26 \%$ & $-38 \%$ & $-14 \%$ & $10 \%$ & \\
\hline & 15 Story & $0 \%$ & $45 \%$ & $38 \%$ & $26 \%$ & $23 \%$ & $0 \%$ & $22 \%$ & $45 \%$ & \\
\hline \multirow{5}{*}{$\stackrel{\Xi}{\sum_{\Sigma}^{e}}$} & 3 Story & $0 \%$ & $43 \%$ & $28 \%$ & $24 \%$ & $18 \%$ & $17 \%$ & $22 \%$ & $43 \%$ & \multirow{5}{*}{$56 \%$} \\
\hline & 6 Story & $0 \%$ & $64 \%$ & $53 \%$ & $42 \%$ & $38 \%$ & $26 \%$ & $37 \%$ & $64 \%$ & \\
\hline & 9 Story & $0 \%$ & $31 \%$ & $33 \%$ & $0 \%$ & $-6 \%$ & $-43 \%$ & $3 \%$ & $33 \%$ & \\
\hline & 12 Story & $0 \%$ & $76 \%$ & $49 \%$ & $35 \%$ & $25 \%$ & $8 \%$ & $32 \%$ & $76 \%$ & \\
\hline & 15 Story & $0 \%$ & $62 \%$ & $12 \%$ & $8 \%$ & $-3 \%$ & $0 \%$ & $13 \%$ & $62 \%$ & \\
\hline \multirow{5}{*}{ 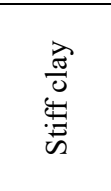 } & 3 Story & $0 \%$ & $35 \%$ & $24 \%$ & $31 \%$ & $29 \%$ & $43 \%$ & $27 \%$ & $43 \%$ & \multirow{5}{*}{$43 \%$} \\
\hline & 6 Story & $0 \%$ & $53 \%$ & $48 \%$ & $34 \%$ & $31 \%$ & $13 \%$ & $30 \%$ & $53 \%$ & \\
\hline & 9 Story & $0 \%$ & $0 \%$ & $48 \%$ & $27 \%$ & $32 \%$ & $-2 \%$ & $18 \%$ & $48 \%$ & \\
\hline & 12 Story & $0 \%$ & $40 \%$ & $38 \%$ & $33 \%$ & $31 \%$ & $24 \%$ & $28 \%$ & $40 \%$ & \\
\hline & 15 Story & $0 \%$ & $31 \%$ & $-2 \%$ & $-1 \%$ & $-7 \%$ & $1 \%$ & $4 \%$ & $31 \%$ & \\
\hline
\end{tabular}

According to Table 14 and Fig. 20, it could be concluded from the average values that, for sandy soils, the SSI impact grows as the subsoil becomes looser, but for clay soils, medium clay produces the strongest SSI effect. the results obtained from Fig. 20 affirm that "sandy soils have a stronger effect on drift than clayey soils". It is important to note that drift is proportional and related to internal forces of the structural members, but displacement isn't proportional to the internal forces; therefore, usually both the drift and the displacement represent the structure behavior together, not independently. 


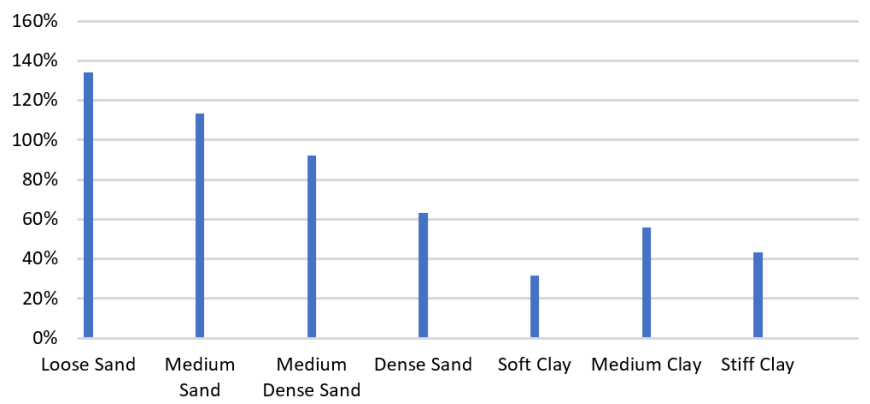

Fig. 20. Average of drift lengthening caused by considering SSI

\section{Evaluating displacement gain due to SSI}

Usually the main objective of analyses is finding internal forces and displacements. Internal forces are directly proportional to the drift, which was discussed in the previous section. in the present section, it is intended to study the effect of subsoil type on the structure displacements.

\subsection{Base displacement}

As mentioned earlier, earthquake input motion could vary from soil type to soil type. the foundation displacement for all subsoil types is discussed here.

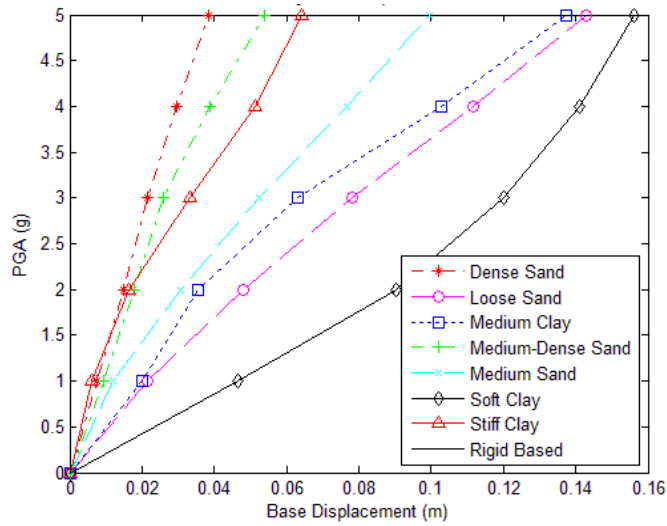

Fig. 21. Base displacement -3 story

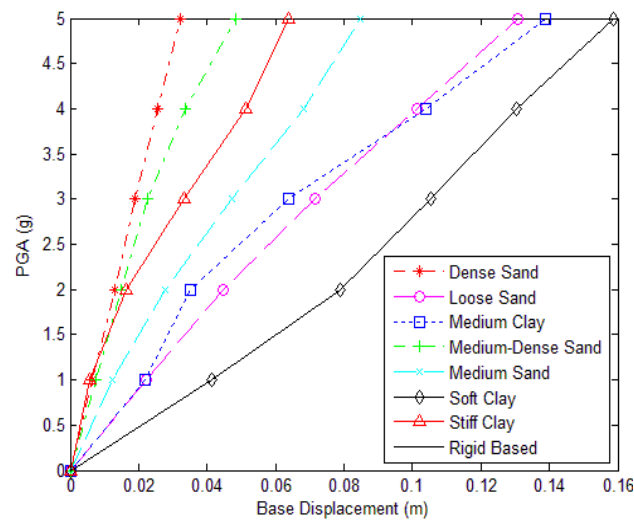

Fig. 23. Base displacement - 9 story

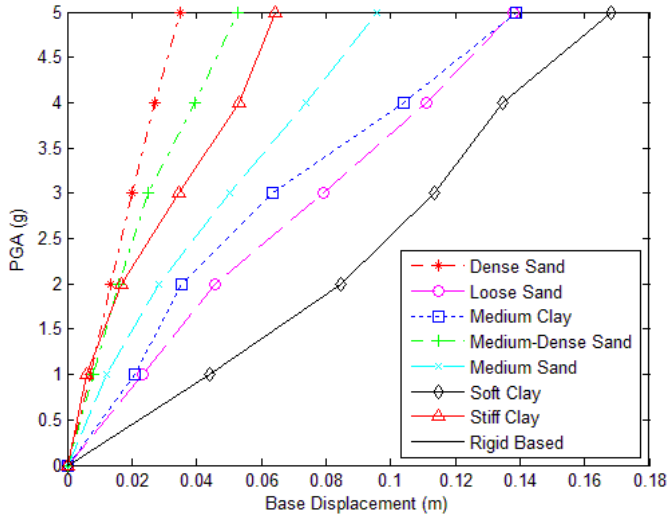

Fig. 22. Base displacement -6 story

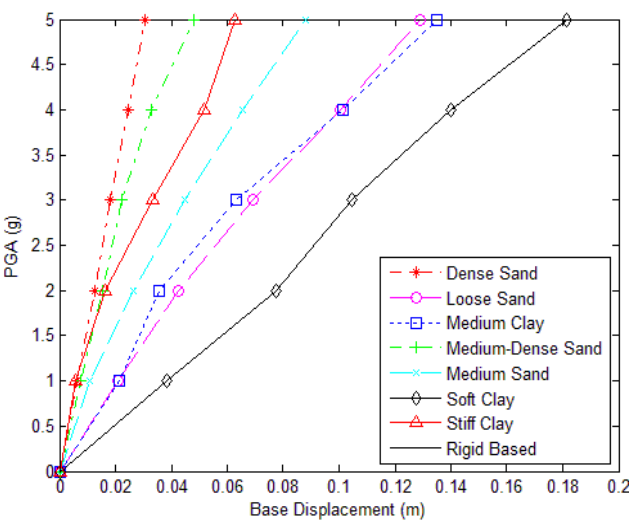

Fig. 24. Base displacement -12 story 


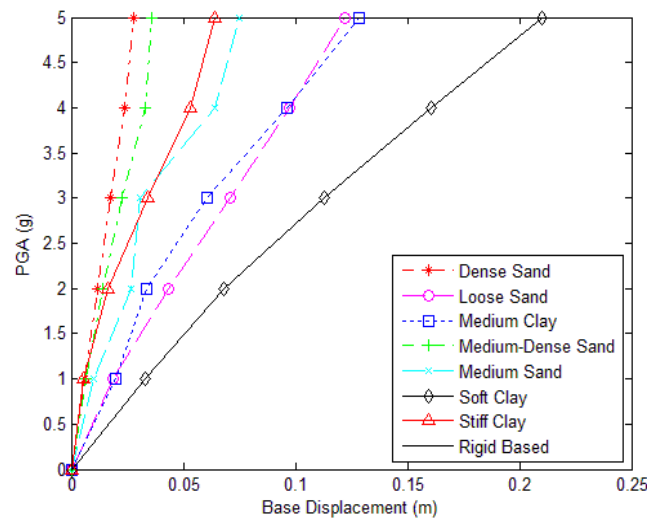

Fig. 25. Base displacement -15 story

As it is obvious, input displacements depend highly on the subsoil types and partially on the structure height. It could be concluded from Figs. 21-25 that the looser the subsoil, the larger the foundation displacement under the action of earthquake. the presence of soft clay results in the highest base displacement values.

\subsection{Roof displacement}

In the previous section, the soil type effect on the input displacement was presented; the present section is aimed at examining the effect of soil type on roof displacement as the response of frames under the action of earthquake.

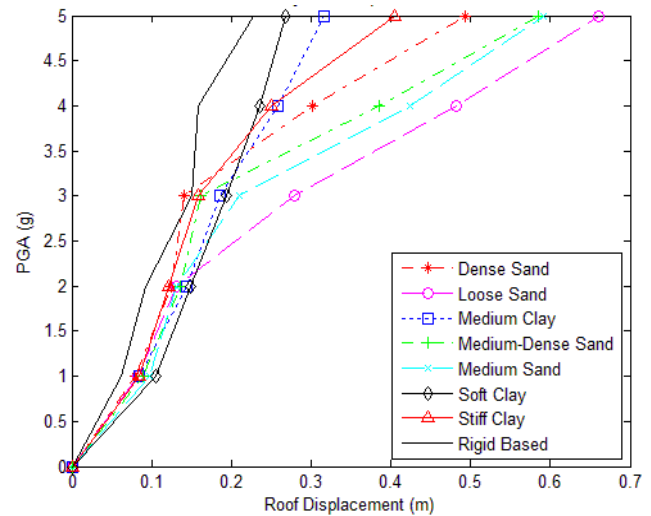

Fig. 26. Roof displacement -3 story

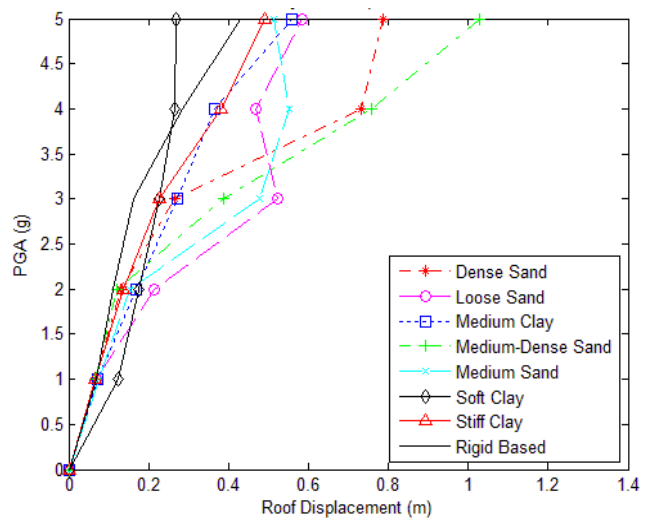

Fig. 27. Roof displacement -6 story

In the case of sandy soils, the largest roof displacement value generally belongs to the frames on the loose sand, and the roof displacement decreases for denser soils. the 3, 6 and 9 story frames on the soft clay have low values of roof displacement, even sometimes less than the rigid based frame, while such frames on the stiff clay produce higher roof displacement values. the frames on the soft clay behave somehow like an isolated structure which produces large base displacements but small inter-story displacements. the 15 story frame on the soft clay is characterized by having a greater roof displacement than the same frame on stiff clay. Simultaneous assessment of roof and base displacements reveals the fact that low and medium rise structures on soft clay behave like a rigid structure with large foundation displacements and low inter-story displacement values. Generally speaking, the largest value of roof displacement belongs to the frames located on loose and medium sand. 


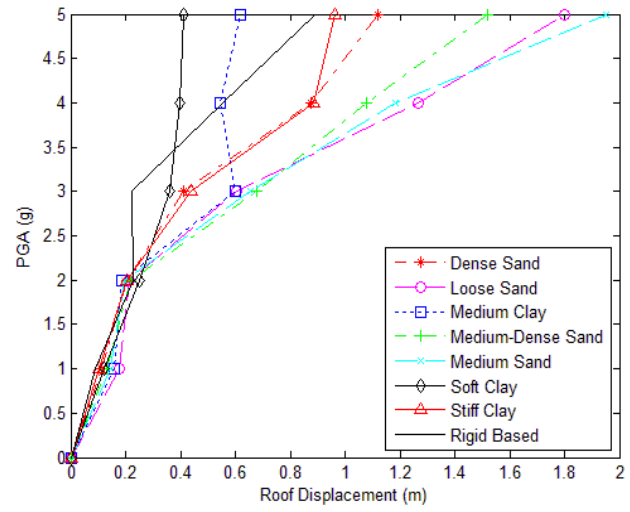

Fig. 28. Roof displacement -9 story

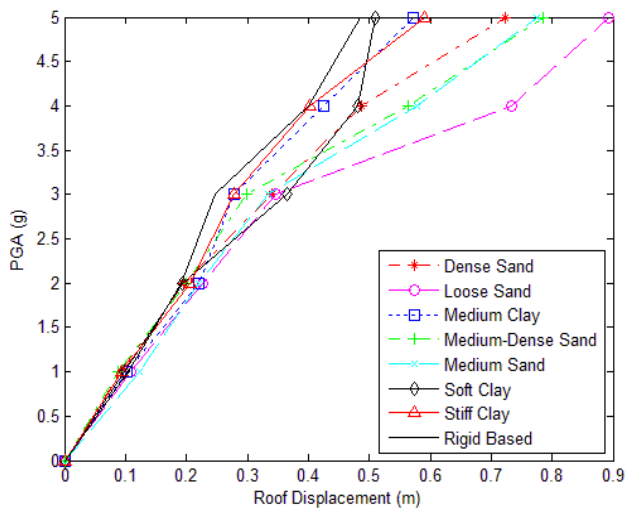

Fig. 29. Roof displacement - 12 story

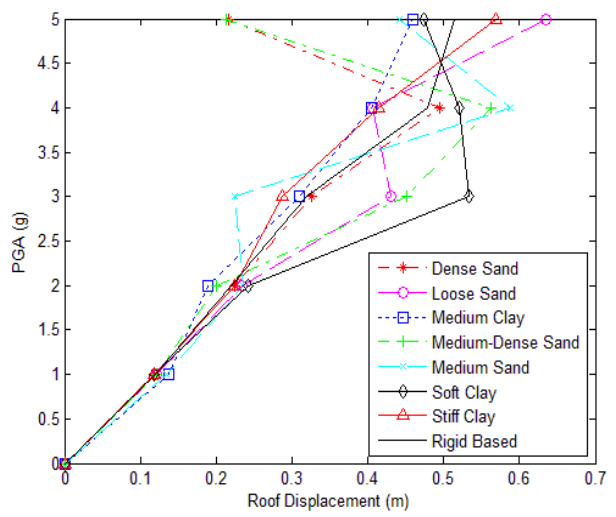

Fig. 30. Roof displacement -15 story

\section{Conclusions}

Seven soil types and five frames are considered in order to investigate the seismic behavior of various soil-structure systems. the innovative idea explored in the present paper is to consider a wide range of soil types and structure heights for examining the structural response trend under the effect of the changes in soil type and structure height. the base and roof displacements and the pushover and IDA curves of each soil-structure system are derived and evaluated. a comparison was made between the responses of the soil in the time and frequency domains. Based on all the aforementioned analyses, the following results are obtained:

1) In the case of sandy soils, the drift intensifies more considerably for looser soils. on the other hand, in the case of clayey sub-soils, for 3 to 12 story frames, the stiff clay causes the most profound drift lengthening, and the soft clay produces the weakest drift lengthening; but with the 15 story frame, the opposite is the case (According to Figs. 13-17).

2) Based on the average values, the effect of SSI on the drift is the strongest for the 6 story frame and is the least powerful for the 15 story frame.

3) Generally speaking, it could be said that for low rise structures, the drift lengthening, caused by SSI, grows with increasing structure height, and for medium rise structures the frame height is not a governing parameter on the SSI effect; lastly for high rise structures, "the taller the structure, the less profound the effect of SSI on the drift" (According to Table 11).

4) The soft clay is the only soil which causes the drift values to be lower than those of fixed-based structures for 3 to 12 story frames, but this soil induces the most considerable drift lengthening for the 15 story frame. This phenomenon can be interpreted by the fact that "soft soil 
deposits amplify low frequency components of earthquake and attenuate high frequency ones, while just the opposite applies for stiff soils; therefore, high rise frames with low natural frequency values would resonate on soft deposits and vice versa" (Based on Figs. 13-17).

5) Generally, stiff soils amplify the responses of low rise structures and may reduce those of high rise structures; the opposite applies for soft soils.

6) The drift of the structure on the soft soil doesn't increase a lot with increasing PGA, confirming that, in the case of soft soils, for high PGA's the soil enters the nonlinear state and doesn't allow the structure to suffer from higher amounts of drift. Such a phenomenon is somewhat similar to the behavior of isolated structures (According to Figs. 13-17).

7) It could be concluded that for taller structures (lower natural frequencies), loose sub-soils alter the responses more significantly than stiff soils, but in the case of short structures (high natural frequency), stiff sub-soils change the responses more substantially than soft soils.

8) Earthquake input displacement (foundation displacement) depends greatly on the subsoil type and partially on frame height. Soft soils induce larger displacements in the foundation (Based on Figs. 21-25).

9) For sandy soils, the looser the subsoil, the larger the roof displacement for all frames.

10) Low and medium rise structures on soft clay exhibit a rigid structural behavior with large foundation displacements and small inter-story displacements; therefore, the roof displacements of low and medium rise frames on the soft clay could even be smaller than those of the rigid base frames (According to Figs. 21-25).

\section{References}

[1] Kramer S. L. Geotechnical Earthquake Engineering. Prentice Hall Upper Saddle River, NJ, 1996.

[2] Sáez E., Lopez-Caballero F. Modaressi-Farahmand-Razavi A. Inelastic dynamic soil-structure interaction effects on moment-resisting frame buildings. Engineering Structures, Vol. 51, 2013, p. 166-177.

[3] Mylonakis G., Gazetas G. Seismic soil-structure interaction: beneficial or detrimental? Journal of Earthquake Engineering, Vol. 4, Issue 3, 2000, p. 277-301.

[4] Wolf J. P. Dynamic Soil-Structure Interaction. Prentice Hall, 1985.

[5] MacMurdo J. Papers relating to the earthquake which occurred in India in 1819: to William Erskine. Esq. \&c. Bombay, 1824.

[6] Mallet R. Great Neapolitan Earthquake of 1857, the First Principles of Observational Seismology as Developed in the Report to the Royal Society of London. London, UK, 1862.

[7] Chopra A. K., Yim S. C.-S. Simplified earthquake analysis of structures with foundation uplift. Journal of Structural Engineering, Vol. 111, Issue 4, 1985, p. 906-930.

[8] ATC A. 40, Seismic Evaluation and Retrofit of Concrete Buildings. Applied Technology Council, Report ATC-40. Redwood City, 1996.

[9] Spyrakos C., Maniatakis C. A., Koutromanos I. Soil-structure interaction effects on base-isolated buildings founded on soil stratum. Engineering Structures, Vol. 31, Issue 3, 2009, p. 729-737.

[10] Zhang J., Tang Y. Evaluating soil-structure interaction effects using dimensional analysis. The 14th World Conference on Earthquake Engineering, 2008.

[11] Dutta S. C., Bhattacharya K., Roy R. Response of low-rise buildings under seismic ground excitation incorporating soil-structure interaction. Soil Dynamics and Earthquake Engineering, Vol. 24, Issue 12, 2004, p. 893-914.

[12] Bárcena A., Esteva L. Influence of dynamic soil-structure interaction on the nonlinear response and seismic reliability of multistorey systems. Earthquake Engineering and Structural Dynamics, Vol. 36, Issue 3, 2007, p. 327-346.

[13] Tang Y., Zhang J. Probabilistic seismic demand analysis of a slender RC shear wall considering soil-structure interaction effects. Engineering Structures, Vol. 33, Issue 1, 2011, p. 218-229.

[14] Raychowdhury P., Singh P. Effect of nonlinear soil-structure interaction on seismic response of low-rise SMRF buildings. Earthquake Engineering and Engineering Vibration, Vol. 11, Issue 4, 2012, p. 541-551. 
[15] Ganjavi B., Hao H. A parametric study on the evaluation of ductility demand distribution in multi-degree-of-freedom systems considering soil-structure interaction effects. Engineering Structures, Vol. 43, 2012, p. 88-104.

[16] Ganjavi B., Hao H. Optimum lateral load pattern for seismic design of elastic shear-buildings incorporating soil-structure interaction effects. Earthquake Engineering and Structural Dynamics, Vol. 42, Issue 6, 2013, p. 913-933.

[17] Abedi-Nik F., Khoshnoudian F. Evaluation of ground motion scaling methods in soil-structure interaction analysis. the Structural Design of Tall and Special Buildings, Vol. 23, Issue 1, 2014, p. 54-66.

[18] Ganjavi B., Hao H., Hajirasouliha I. Influence of higher modes on strength and ductility demands of soil-structure systems. Journal of Earthquake and Tsunami, Vol. 10, 2016, p. 1650006.

[19] Haiyang Z., Zhonghua H., Guoxing C. Numerical modeling on the seismic responses of a large underground structure in soft ground. Journal of Vibroengineering, Vol. 17, Issue 2, 2015, p. 14.

[20] Xiong W., Jiang L. Z., Li Y. Z. Influence of soil-structure interaction (structure-to-soil relative stiffness and mass ratio) on the fundamental period of buildings: experimental observation and analytical verification. Bulletin of Earthquake Engineering, Vol. 14, Issue 1, 2016, p. 139-160.

[21] He Z. W., Shang S. P., Liu F. C., et al. Experimental study on fundamental frequency of soil-structure dynamic interaction system. Journal of Railway Science and Engineering, Vol. 5, 2008, p. 16-20.

[22] Haidong S. S. X. W. W., Fei L. K. Y. SSI effects on the dynamic behavior of structures: experimental study on a 1/4 scaled steel-frame building prototype. China Civil Engineering Journal, Vol. 5, 2009, p. 021.

[23] Tsai C., Hsueh C., Su H. Roles of soil-structure interaction and damping in base-isolated structures built on numerous soil layers overlying a half-space. Earthquake Engineering and Engineering Vibration, Vol. 15, Issue 2, 2016, p. 387-400.

[24] Abedi-Nik F., Khoshnoudian F. Deflection modification factors of multistory buildings considering soil-structure interaction. Earthquake Engineering and Engineering Vibration, Vol. 14, Issue 3, 2015, p. 561-570.

[25] Nehrp Consultant Joint Venture Soil Structure Interaction for Building Structures. National Institiute of Standards and Technology, 2012.

[26] Gajan S., Kutter B. L. Capacity, settlement, and energy dissipation of shallow footings subjected to rocking. Journal of Geotechnical and Geoenvironmental Engineering, Vol. 134, Issue 8, 2008, p. 1129-1141.

[27] Mazzoni S., McKenna F., Scott M. H., et al. Open System for Earthquake Engineering Simulation (Opensees). User Command Language Manual. University of California, Pacific Earthquake Engineering Research Center, Berkeley, 2006.

[28] Kent D. C., Park R. Flexural members with confined concrete. Journal of the Structural Division, Vol. 97, Issue 7, 1971, p. 1969-1990.

[29] Saatcioglu M., Razvi S. R. Strength and ductility of confined concrete. Journal of Structural Engineering, Vol. 118, Issue 6, 1992.

[30] Priestley M., Paulay T. Seismic Design of Reinforced Concrete and Masonry Buildings. John Wiley and Sons, New York, 1992.

[31] Council B. S. S. NEHRP Recommended Seismic Provisions for New Buildings and Other Structures (FEMA P-750). Federal Emergency Management Agency, Washington, 2009.

[32] Lysmer J., Kuhlemeyer R. Finite element model for infinite media. Journal of Engineering Mechanics, ASCE, Vol. 95, 1969, p. 859-77.

[33] Clough R. W., Penzien J. Dynamics of Structures. Computers and Structures, USA, 1975.

[34] Scott M. H., Fenves G. L. Krylov subspace accelerated Newton algorithm: application to dynamic progressive collapse simulation of frames. Journal of Structural Engineering, Vol. 136, Issue 5, 2010.

[35] Newmark N. M., Hall W. J. Earthquake Spectra and Design. Earth System Dynamics, 1982.

[36] Vamvatsikos D., Cornell C. A. Incremental dynamic analysis. Earthquake Engineering and Structural Dynamics, Vol. 31, Issue 3, 2002, p. 491-514.

[37] Kausel E. Early history of soil-structure interaction. Soil Dynamics and Earthquake Engineering, Vol. 30, Issue 9, 2010, p. 822-832.

[38] Arefi M. J. Effects of Soil-Structure Interaction on the Seismic Response of Existing R.C. Frame Buildings. Istituto Universitario di Studi Superiori di Pavia, Università degli Studi di Pavia, 2008. 


\section{Appendix}

$f_{c}$ represents the concrete peak strength $[\mathrm{Pa}]$ in compression, and $f_{u}$ is the residual strength [Pa] of concrete. $\varepsilon_{0}$ and $\varepsilon_{u}$ show the strain [\%] at peak strength and the ultimate compressive strain [\%] of concrete respectively. the terms $\varepsilon_{u c}$ and $\varepsilon_{u o}$ are the ultimate compressive strain [\%] of confined and unconfined concrete respectively, while $\varepsilon_{u s}$ is the ultimate strain [\%] of the reinforcing steel in tension. $\rho_{v}$ and $f_{y h}$ show the volumetric ratio [\%] and yield stress [Pa] of confining steel respectively. the peak strength $[\mathrm{Pa}]$ of confined concrete in compression is expressed by $f_{c c}$.

$C_{n}$ and $C_{s}$ are normal and shear damping [\%] of Lysmer-Kuhlemeyer dashpot. $\rho$ and $v$ represent the mass density $\left[\mathrm{N} / \mathrm{m}^{2}\right]$ and the Poisson ratio [\%] of soil respectively. the terms $v_{p}$ and $v_{s}$ are the propagation velocity $[\mathrm{m} / \mathrm{s}]$ of dilatational and shear waves respectively. $G_{r}$ and $B_{r}$ indicate low strain shear modulus $[\mathrm{Pa}]$ and the bulk modulus $[\mathrm{Pa}]$ of the considered soil. $f$ and $c$ stand for the friction angle [Deg] and the apparent cohesion $[\mathrm{Pa}]$ of the soil. $\gamma_{\max }$ shows the octahedral shear strain [Deg] at which the maximum shear strength is reached, and $P_{r}$ presents the reference mean effective confining pressure [Pa] at which $G_{r}, B_{r}$ and $\gamma_{\max }$ are defined. Shear wave velocity $\left[\mathrm{m} / \mathrm{s}\right.$ ] and shear modulus [Pa] of the soil are shortened to $V_{s}$ and $G$ respectively. $H$ and $T$ stand for the depth [m] and period [s] of the soil layer respectively. $h, B, L$ and $T^{\prime}$ respectively represent the structure height [m], foundation width $[\mathrm{m}]$, foundation length $[\mathrm{m}]$, and first mode period [s] of the structure. the term $\bar{T}$ denotes the soil-structure system period [s].

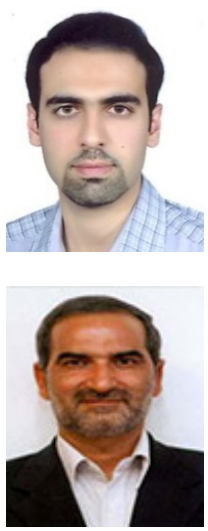

Elyar Zafarkhah was born in 1988. He received Master's degree after two years of study at Sharif University of Technology. He is now pursuing his Ph.D. in structural engineering from Iran University of Science and Technology, Iran, Tehran. His current research interests include nonlinear time history analysis and soil-structure interaction.

Morteza Raissi Dehkordi is now working as an Assistant Professor in Iran University of Technology with a total of ten years of experience. He has specialized in the field of earthquake resistance buildings. 